\title{
WestVirginiaUniversity
}

THE RESEARCH REPOSITORY @ WVU

Graduate Theses, Dissertations, and Problem Reports

2021

\section{Predictors of Courage in Adolescents}

Yea Won Park

yp0013@mix.wvu.edu

Follow this and additional works at: https://researchrepository.wvu.edu/etd

Part of the Developmental Psychology Commons

\section{Recommended Citation}

Park, Yea Won, "Predictors of Courage in Adolescents" (2021). Graduate Theses, Dissertations, and Problem Reports. 10182.

https://researchrepository.wvu.edu/etd/10182

This Thesis is protected by copyright and/or related rights. It has been brought to you by the The Research Repository @ WVU with permission from the rights-holder(s). You are free to use this Thesis in any way that is permitted by the copyright and related rights legislation that applies to your use. For other uses you must obtain permission from the rights-holder(s) directly, unless additional rights are indicated by a Creative Commons license in the record and/ or on the work itself. This Thesis has been accepted for inclusion in WVU Graduate Theses, Dissertations, and Problem Reports collection by an authorized administrator of The Research Repository @ WVU. For more information, please contact researchrepository@mail.wvu.edu. 
Graduate Theses, Dissertations, and Problem Reports

2021

Predictors of Courage in Adolescents

Yea Won Park

Follow this and additional works at: https://researchrepository.wvu.edu/etd

Part of the Developmental Psychology Commons 
Predictors of Courage in Adolescents

\author{
Yea Won Park, B.S. \\ Thesis submitted to the \\ Eberly College of Arts and Sciences \\ at West Virginia University \\ in partial fulfillment of the requirements \\ for the degree in
}

\author{
Master of Science \\ in \\ Psychology - Life-Span Developmental Psychology
}

\author{
Amy Gentzler, Ph.D. Chair \\ Nick Turiano, Ph.D. \\ Amy Root, Ph.D. \\ Department of Psychology
}

Morgantown, West Virginia

2021

Keywords: Courage, Adolescents, Positive Youth Development, Emotion Regulation, Parenting Copyright 2021 Yea Won Park 


\author{
Abstract \\ Predictors of Courage in Adolescents
}

Yea Won Park

Adolescence can be a difficult phase of life. Adolescents may experience drastic physical, psychological, social changes, which can lead to uncertainty and anxiety. Courage is an important construct to study because it could help adolescents carry out tasks, work more effectively, and pursue goals (Koerner, 2014). Few studies have investigated predictors of general courage (e.g., personality; Muris et al., 2009), and moral courage (i.e., parenting, gender; Bronstein et al., 2009). The present study examined intrapersonal and interpersonal predictors (Time 1) of courage (Time 3 ) among adolescents, as well as potential mediating and moderating mechanisms. Data were collected from a larger longitudinal study with 3 time points and the present study's data used Time 1 and Time 3 (one year apart). The sample included 203 adolescents (51.7\% girls, $\left.M_{a g e}=15.08\right)$. Hierarchical multiple regression models indicated that autonomy support of mothers and fathers, self-esteem, and cognitive reappraisal at Time 1 were positively associated with adolescent courage at Time 3 , whereas maternal helicopter parenting negatively related with adolescent courage at Time 3, over and above gender and socioeconomic status. Findings from exploratory mediation models demonstrated that autonomy support of parents predicted greater self-esteem, which explained greater courage. Anxious and avoidant attachment of parents predicted less self-esteem, which in turn explained less courage. In addition, cognitive reappraisal indirectly linked avoidant attachment to mothers, maternal helicopter parenting, and courage (more avoidantly attached to mothers reported less cognitive reappraisal and less courage; and greater maternal helicopter parenting related with more cognitive reappraisal and greater courage). This study contributes to the limited empirical research on courage as well as the first to examine predictors which may contribute to adolescents' development of courage.

Keywords: Courage, Adolescents, Positive Youth Development, Emotion Regulation, Parenting

Keywords: Courage, AdolesTcents, Positive Youth Development, Emotion Regulation, Parenting 


\section{TABLE OF CONTENTS}

I. Abstract (ppii)

II. Introduction (pp1-16)

III. Methods (pp16-22)
a. Participants (pp16-17)
b. Procedure (pp 17-18)
c. Measures (pp18-22)

IV. Results (pp22-30)
a. Preliminary analyses (pp22-25)
b. Primary analyses (pp25-30)

V. Discussion (pp30-41)

VI. References (pp42-60)

VII. Table 1: Summary of Sex, Age, and Race/Ethnicities of Sample (pp61)

VIII. Table 2: Summary Statistics of Variables and Transformed Variables (pp62)

IX. Table3: Correlations between Time 1 Intrapersonal and Interpersonal Predictors and Time 3 Courage (pp63)

X. Table 4: Hierarchical Regression Analysis for Interpersonal Predictors of Time 3 Courage (pp64)

XI. Table 5: Hierarchical Regression Analysis for Intrapersonal Predictors of Time 3 Courage (pp65)

XII. Figure 1: Mediating Effect of Self-esteem on the Relationship between Autonomy Support of Mother and Courage (pp66) 
XIII. Figure 2: Mediating Effect of Self-esteem on the Relationship between Autonomy Support of Father and Courage (pp66)

XIV. Figure 3: Mediating Effect of Self-esteem on the Relationship between AttachmentAnxious to Mother and Courage (pp67)

XV. Figure 4: Mediating Effect of Self-esteem on the Relationship between AttachmentAnxious to Father and Courage (pp67)

XVI. Figure 5: Mediating Effect of Self-esteem on the Relationship between AttachmentAvoidant to Mother and Courage (pp68)

XVII. Figure 6: Mediating Effect of Self-esteem on the Relationship between AttachmentAvoidant to Father and Courage (pp68)

XVIII. Figure 7: Mediating Effect of Cognitive Reappraisal on the Relationship between Attachment-Avoidant to Mother and Courage (pp69)

XIX. Figure 8: Figure 6: Mediating Effect of Cognitive Reappraisal on the Relationship between Helicopter Parenting of Mothers and Courage (pp69)

XX. Appendices (pp70-81)

a. Appendix A: Measures (pp70-77)

b. Appendix B: Additional Analyses with Neuroticism as a Covariate (pp77-81)

i. Tables and Figures for Analyses including Neuroticism (pp82-87) 


\section{Predictors of Courage in Adolescents}

Adolescence is a taxing period for many individuals as they experience changes in their physical, social, and psychological realms. These drastic changes may lead to experiencing uncertainty and anxiety. In addition, literature on risk-taking suggest that developmental changes in the brain (e.g., mismatch between prefrontal cortex and amygdala) and psychosocial factors (e.g., social situations) contribute to greater risk-taking behavior during adolescence (Steinberg, 2004; 2007). Although past research has rather focused on negative patterns of risk, a relatively recent push argues for the significance of positive risk-taking (defined as "socially acceptable and constructive risks" Duell \& Steinberg, 2019, p.1), as such behaviors may influence adolescent flourishing (Duell \& Steinberg, 2021). In times of uncertainty and fear, courage may serve as a protective factor by providing the means to move forward, contributing to positive identity development, interfere with the development of fear and anxiety, working more effectively, and also pursuing goals (Howard et al., 2016; Koerner, 2014; Muris et al., 2009; Sarros \& Cooper, 2006; Springer, 2012). Thus, it is important to explore the influence of courage during adolescence, a period of heightened negative and positive risk-taking behavior (Duell \& Steinberg, 2021). Courage is often defined as (a) "a willful intentional act, (b) executed after mindful deliberation, (c) involving substantial risk to the actor, (d) primarily motivated to bring about a noble good or worthy end, (e) despite perhaps the presence of the emotion of fear" (Rate et al., 2007, p.95). Despite the potential role of courage as a protective factor for youth, little research has considered predictors of courage development in adolescents. By learning more about factors that predict courage, we can better understand why some adolescents have the cognitive and emotional strength to accomplish goals and experience positive outcomes. Thus, more work is needed to understand predictors of courage. In the present study, interpersonal 
factors (i.e., attachment styles, parenting) and intrapersonal competencies (i.e., self-esteem and emotion regulation skills), which are measured at Time 1 are investigated. The present study provides new evidence on which individual characteristics and interpersonal predictors promote courage (Time 3, 1-year apart) development among adolescents.

\section{The Importance of Courage}

Courage has been commended across western and eastern cultures and by many philosophers such as Aristotle, Plato, and scholars for many years (Dahlsgaard et al., 2005). The practice of courage is important as it can counteract fear and anxiety, work as a governing virtue by motivating and facilitating individuals to pursue a positive course of action, and influence positive identity development (Harris, 1999; Muris et al., 2009; Springer, 2012; Srivastva \& Cooperrider, 1998). In addition, courageous people experience an enhanced sense of personal integrity, the ability to be more appreciative and confident, and an awareness of their interpersonal and intrapersonal assets (Finfgeld, 1999). In her meta-analysis, Finfgeld (1999) notes that courageous individuals also may have the ability to fully embrace life, respond to the needs of others, and succeed, whereas less courageous individuals may be more likely to surrender to anxiety or become depressed. Courageous individuals also can be role models to their peers by offering a vicarious learning opportunity (Worline, 2010). A cross-sectional study with Korean college students found that courage had a negative association with internet addiction (Choi et al., 2015). Moreover, virtue theory (Adams, 2006) states that courage is the essential steward, which enables one to engage and persistently initiate actions to endure the unpredictable nature of life circumstances (Kim et al., 2016). Courage could perhaps be a key source that galvanizes individuals to put forth effort to maintain motivation, seek selfimprovement, encourage commitment, and develop personal resources. 


\section{Defining Courage}

There have been many attempts to define courage, though its subjective nature makes it difficult for researchers to construct an operative definition (Lopez et al., 2003). Some authors favor an explicit approach to defining and measuring courage whereas others view courage via an implicit-theory approach. An explicit theorist will quantify courage using more objective data collection. For example, Cox, Hallam, O’Conner and Rachman's (1983) research involved quantifying and comparing physiological responses of bomb operators and nondecorated bomb operators during stressful tasks. Compared to the nondecorated bomb operators, the decorated bomb operators had lower cardiac reactivity and were identified as courageous. On the other hand, implicit theories examine people's own cognitive constructions (Rate et al., 2007; Sternberg, 1985). Therefore, an implicit measurement may examine participants' notions of what they believe defines courage (O'Bryne et al., 2000). In the present study, an implicit measure is used as adolescents are asked to reflect on and rate their own level of courage.

As theories of courage evolved, different types of courage have been introduced. These different types of courage are often characterized by the type of risk involved. For example, psychological courage is the strength to confront and work through destructive habits, irrational anxieties, and psychological control (Putman, 1997). Moral courage is defined as "the behavioral expression of authenticity in the face of the discomfort of dissension, disapproval, or rejection" (Lopez et al., 2010, p. 23). Social courage is defined as "risk-taking in pursuit of socially valued goals" (Larsen \& Giles, 1976, p. 300). Existential psychologists offered hardiness (defined as the embracement of viewpoints of commitment, control, and challenge) as an operationalization of existential courage (Maddie, 2004). Finally, physical courage is when the risk is related to one's physical harm (Woodward \& Pury, 2007). Adolescent participants in the present study may be 
thinking of these various types of courage, though they are not asked to explicitly consider different types.

Within positive psychology, courage is categorized as one of the six core moral virtues (e.g., wisdom, humanity, justice, temperance, and transcendence). The virtue of courage is defined as "emotional strengths that involve the exercise of will to accomplish goals in the face of external or internal opposition" (Peterson \& Seligman, 2004, p.44). Virtues are universally appreciated characteristics, whereas, character strengths are processes which display those virtues. For example, the virtue of courage can be achieved through bravery, persistence, integrity, and vitality. Within this framework, bravery is simply the capacity to do something despite fear. On the other hand, courage encompasses not only the observable acts but also the cognitive, emotional, motivational, and decisions processes which bring about the observable acts (Peterson \& Seligman, 2004).

To better assess the different components of courage, some researchers used implicit measures to investigate how individuals conceptualized courage (Rate et al., 2007). Rate and his colleagues (2007) examined numerous definitions and types of courage based on open-ended questionnaire responses from undergraduate and graduate students, conducted exploratory factor analyses, and found four necessary components of people's notions of courage: a) intentionality/deliberation, b) personal fear, c) noble/good act, and d) known personal risk. This study made it possible to dissemble courage into measurable components. Based on this study, to date, the most prevalent definition of courage defines the attribute as a "willful, intentional act executed after mindful deliberation, usually in the presence of fear" (Rate et al., 2007, p.95). To date, few studies have empirically examined the construct of courage among adolescents, and few have examined different types of courage. For instance, only one study has examined the 
longitudinal association between parenting and moral courage among adolescents (Bronstein et al, 2007). Because adolescents may perceive different types of behaviors as courageous it may be best to utilize a broader measure of courage to better understand what the individual considers courageous. Thus, the present study will be the first to examine multiple predictors of general courage within the same study, thereby contributing to the literature on the development of courage during adolescence.

\section{Courage Across the Lifespan}

Although there have been several studies on courage (the constructs and its components), few studies have examined the concept of courage from a developmental perspective. Szagun (1992) was the first to examine courage with a developmental approach. Szagun's study assessed whether there were different manifestations of courage across different age groups. The study echoed the idea that in order to acquire the concept of courage, children need to have the ability to shift from concrete to abstract notions (Gentner, 1988; Piaget, 1977). Szagun's (1992) crosssectional study compared three age groups of 5 to 6 years, 8 to 9 years, 11 to 12 years old. The older age group defined courage in more psychological terms (e.g., sticking to one's belief), whereas the younger age group understood courage in physical terms (e.g., saving someone from a fire), and the middle age group had similarities to both groups by emphasizing moral risks along with physical risks. Overall, this study (Szagun, 1992) was important in establishing the presence of age-associated differences in perceptions of courage.

To further understand courage developmentally, additional research has examined the construct of courage in varying aged youth. A study was conducted to explore the construct of courage in youth (8 to 13 years old) and its relationship with anxiety and personality traits (Muris et al., 2009). Their results indicated that the personality traits of extraversion and 
openness/intellect were positively related to higher levels of courage whereas agreeableness was negatively related to courage levels. Results also showed that courage explained a significant portion of anxiety scores in that there was a significant negative relationship between courage and anxiety symptoms. Interestingly, the study showed that $21 \%$ of variance in reported courage scores was explained by the "Big Five" personality traits. Although that suggests personality traits do play a role, it also indicates that there may be multiple other variables that explain children's courage levels.

\section{Potential Predictors of Courage}

Self-esteem. As self-esteem refers to one's self-worth and efficacy (Gecas \& Schwalbe, 1986), it may be presumed that self-esteem could be an important predictor of courage. Selfesteem comprises the individual's belief of one's value and self-worth (Coopersmith, 1967). Because higher self-esteem suggests having more confidence in one's abilities, adolescents with higher self-esteem could be encouraged to willingly stand up for their beliefs despite the presence of uncertainty (Sonnentag \& Barnett, 2013; Sonnentag \& Barnett, 2016). Results from studies with college students indicated that those with higher self-esteem were more likely to associate success to internal causes, whereas those with lower self-esteem were more likely to attribute positive outcomes to external causes (Ickes \& Layden, 1978, Marsch et al., 1984). Therefore, people who ascribe good outcomes to their own actions may potentially be more inclined to engage in courageous acts. Furthermore, self-esteem relates to self-efficacy and one's ability to make a difference (Blascovich \& Tomaka, 1991; Rosenberg, 1989). Thus, adolescents with high self-esteem would likely be more confident that they could make a positive impact. Additionally, self-esteem relates to internal beliefs regarding present situations the future (Marsch et al., 1984; Nurmi \& Pulliainen, 1991). Nurmi and Pulliainen (1991) further speculated 
that these findings may be due to the fact that individuals with high self-esteem could have the courage to generate future-oriented goals. Therefore, it is hypothesized that adolescents with high self-esteem may in turn be motivated to take action when faced with challenges.

Emotion regulation. One potentially important predictor of courage may be emotion regulation skills. Emotion regulation is the ability to adjust and modify the experience and expression of emotions (Gross \& Thompson, 2007; Lennarz et al., 2017). Adolescence is a period when adolescents experience mood fluctuations, an increased sense of autonomy, higher levels of negative mood, and have a heightened sensitivity to positive or rewarding experiences (Schweizer et al., 2020; Spear, 2011). Adolescence is a critical time for adolescents to learn how to regulate emotions more independently (Steinberg, 2008). It has been suggested that emotion regulation plays a role in helping adolescents successfully endure the developmental challenges they encounter (Riediger \& Klipker, 2014).

While there are many ways to regulate emotion, the current study will focus on two commonly assessed emotion regulation strategies: cognitive reappraisal and expressive suppression. Cognitive reappraisal is an antecedent-focused strategy that involves the reinterpretation of an emotion-triggering event in order to change its emotional impact (e.g., when one is stressed about final exams, he/she reframes that summer break is coming; Gross, 1998). Expressive suppression is a response-focused strategy that (i.e., trying not to express distress after watching a sad movie) which involves actively inhibiting the observable expression of emotional experience (e.g., trying not to express distress after watching a sad movie; Gresham \& Gullone, 2012; Gross, 1998; Gross \& Thompson, 2007). In general, research indicates that greater use of reappraisal in adults and adolescents is linked to more positive outcomes (e.g., greater self-esteem, higher well-being; Gross \& Cassidy, 2019; Gross \& John, 2003). In contrast, 
suppression is often linked to negative outcomes (e.g., more depressive and anxiety symptoms, psychological distress, self-injury, and lower executive functioning skills; Betts et al., 2009; Gross \& John, 2003; Gross \& Cassidy, 2019; Hasking et al., 2010; Lantrip et al., 2015; Schäfer et al., 2016). This study will explore a previously unexamined question of whether particular emotion regulation strategies may promote courage in youth.

When an individual utilizes cognitive reappraisal, he/she is manipulating the meaning of the stimulus to reduce negative affect. In other words, cognitive reappraisal signifies using cognitive abilities to reframe and alter one's perspective of an emotional situation. The strategy acknowledges that one's emotional thoughts are associated to how individuals appraise their emotions. A brain imaging study found that younger adults were better at using reappraisal to decrease unpleasant emotion than older adults, whereas older adults were more successful utilizing reappraisal to upregulate negative emotion (Opitz et al., 2009). These results suggest that cognitive reappraisal aid younger adults to successfully downregulate the subjective experience of negative emotions. Therefore, utilization of cognitive reappraisal could be potentially useful during courageous acts, which require emotional tenacity in the face of risky or daunting stimuli. Thus, individuals who actively engage in cognitive reappraisal may be more effective at reducing negative affect, resulting in greater emotional strength to exercise their intentions and ability to be more courageous.

Suppression is widely viewed as a maladaptive emotion regulation strategy/associated with negative outcomes. However, suppression may be beneficial with high-intensity emotions (Bonanno et al., 2004; Gardner et al., 2019; Mauss \& Butler, 2010). In stressful situations, engaging in suppression may aid adolescents to efficaciously curtail their distress and achieve their intended goal. Suppression could stimulate an adolescent to work more effectively. Thus, 
although the use of suppression has never been examined in relation to courage, it is possible that it correlates with higher levels of courage. Because courageous acts are done mainly in the presence of fear and uncertainty, it may be advantageous to be able to suppress negative or fearful emotions in order to willingly and deliberately act courageously. In this manner, adolescents can utilize a strategy like suppression to better express and demonstrate courage.

Attachment to parents. Bowlby's attachment theory (1969) suggests that infants develop an internal working model of attachment as they amass interactions and experiences with caregivers. Such information guides infants to synthesize their expectations of others, explore their environment, and further comprehend how the world operates (Bowlby, 1982). The infant-caregiver relationship establishes the foundation for future relationships dynamics. In infancy, the function of the attachment system is primarily for ensuring the physical safety of the infant through proximity to caregivers. The attachment system begins as a dyadic relationship but the attachment style is further carried out by the child throughout other relationships (Koehn \& Kerns, 2018). Attachment is part of a broader part of parenting practices that captures parentchild relationships.

Ainsworth et al., (1978) further identified three styles of attachment: secure, anxiousresistant, and anxious-avoidant. Each pattern is associated with different patterns of motivation, behavior, emotional response, and regulation in response to stressful situations. For instance, the more avoidant child is associated with a pattern to be more self-reliant and to suppress emotions in response to threat (Bartholomew \& Horowitz, 1991; Doyle et al., 2009). While traditional attachment measures assessed attachment based on the three attachment types, recent attachment measure development suggests assessing attachment in terms of two dimensions of anxiety and avoidance (Brennan et al., 1998; Mikulincer \& Shaver, 2007). Individuals are characterized as 
anxious based on fear of rejection and preoccupation with attachment needs and attachment figures, whereas individuals characterized as avoidant are based on the extent of discomfort they have with closeness and not using attachment figures as a secure base (Brennan et al., 1998; Lee \& Hankin, 2009).

Longitudinal research from birth to young adulthood has shown that attachment dynamics influence the cognition, interpersonal behavior, emotion regulation, self-esteem, and mental health (Grossman et al., 2005; Mikulincer et al., 2009). For example, when securely attached, children and adolescents report lower levels of anxiety, and can cultivate a sense of mastery, competence, and confidence to approach novel experiences and tasks, and an ability to ask for help (Sroufe, 2005; Thompson, 2008). In addition, research has shown that secure attachment in adolescence predicted healthier coping strategies, higher self-esteem, and more optimistic appraisals of potentially threatening events (Mikulincer \& Shaver, 2007; Mikulincer, et al., 2009).

In contrast to secure attachment, insecure attachment is generally associated with more negative outcomes. For instance, research found that insecure attachment in adolescents is associated with anxiety symptoms, low self-esteem and dysfunctional attitudes (Gamble \& Roberts, 2005; Lee \& Hankin, 2009; Muris \& Meesters, 2002). Previous work suggests that adolescents high in attachment anxiety may more likely engage in negative cognitive processes and not have a protective buffer (e.g., high self-esteem or social support) to further alter their cognitive processes with a more functional approach (Gamble \& Roberts, 2005). Also, individuals high in anxiety dimensions are characterized as employing hyperactivating strategies (e.g. up-regulating and maintaining negative emotions) rather than using regulation such as 
cognitive reappraisal or suppression (Mikulincer et al., 2003). Therefore, it is expected that adolescents with anxious attachment will have less courage.

On the other hand, adolescents who are higher on the avoidant attachment dimension may not actively engage or seek support to challenge their cognitive distortions (Feeney et al., 2008). Some research might suggest that avoidance should relate to less courage because these individuals tend to stunt exploration as they do not have a secure base (Aspelmeier \& Kerns, 2003). As the internal working model suggests, those higher on the avoidant dimension may have less empathy and expectations for relationship connections, which could relate to less courage (Mikulincer et al., 2001; Spielmann et al., 2013). However, at the same time, individuals high on the avoidant dimension tend to suppress emotions and be independent (Mikulincer \& Arad, 1999; Mikulincer et al., 2004). The latter tendency may promote adolescents to be assertive and have greater courage. Moreover, a study conducted with undergraduate students found a significant negative correlation between avoidance attachment and agreeableness (Noftle \& Shaver, 2006). Although reverse effect associations may be found, Noftle and Shaver (2006) suggest that avoidant individuals' self-reliant nature may promote greater willingness engage in courageous behaviors.

Parenting behaviors. The belief that parents are influential in their children's development has been empirically supported (e.g., Griffin et al., 2000). If parental efforts affect children directly or indirectly, parenting behavior can also serve as a potential important predictor of adolescent courage. The present study will specifically focus on parental behaviors which support autonomy development as adolescent autonomy may be especially important in courageous behaviors (Hannah et al., 2007). In general, research indicates that parental controlling behavior is associated with negative outcomes (e.g., Barber, 1996). In contrast, 
parental behavior that supports adolescents' autonomy is associated with positive outcomes (e.g., higher self-esteem and self-efficacy; Reed et al., 2016; Ryan et al., 1994). Previous research has shown that supportive and responsive parenting predicted moral courage in $12^{\text {th }}$ grade adolescent girls, though no association was found for boys (Bronstein et al., 2007). This study expands on these findings by exploring whether autonomy support and helicopter parenting predicts courage among adolescents.

Parental autonomy support refers to the parenting behaviors which encourage the child's self-initiating behavior and volitional functioning and support their child's decisions (Grolnick \& Ryan, 1989). Autonomy supportive parenting style is congruent with high levels of parental involvement and structure (Joussemet et al., 2008). Various studies with adolescent samples has shown that perceived autonomy support is accompanied with adaptive developmental outcomes. For instance, a longitudinal study conducted with undergraduate students discovered that maternal autonomy support predicted decreases in suppression (Brenning et al., 2015). Also, an empirical study found correlational evidence between parental autonomy support and self-esteem (Robbins, 1994). As research supports that autonomy supportive parenting is associated with higher self-esteem and lesser use of suppression, it is also expected that autonomy supportive parenting style will also increase courage in youth.

When parents engage in excessive involvement in their children's or adolescents' lives, this parenting style is defined as overparenting or helicopter parenting (Cline \& Fay, 1990). Research has shown that helicopter parenting is associated with children having lower wellbeing, a decreased sense of autonomy, less problem-solving skills, and more internalizing problems (Darlow et al. 2017; Padilla-Walker \& Nelson, 2012; Segrin et al. 2012; Schiffrin, et al., 2013). However, there are contradicting findings related to the role of helicopter parenting 
and child outcomes. Some studies suggest that there is no association between well-being and helicopter parenting (e.g., Lampert 2009; Reed et al. 2016; Schiffrin et al., 2019). Some even suggest that helicopter parenting is associated with positive outcomes, such as college students showing higher levels of life satisfaction, having clearer life goals, and perceiving parents as emotionally supportive (Fingerman et al. 2012; Padilla-Walker \& Nelson 2012). Although the contradicting findings made it difficult to predict the association between helicopter parenting, it is speculated that those who experienced helicopter parenting could be less courageous as they could have less autonomy and low self-efficacy.

Gender Although the construct of courage is considered to be influenced by gender stereotypes, not many studies have investigated the role of gender in courage. To date, only a single longitudinal study found that supportive and responsive parenting from mothers and fathers was associated with an increased in moral courage for $12^{\text {th }}$ grade adolescent girls (Bronstein et al., 2007). For boys, parenting did not predict moral courage (Bronstein et al., 2007). Prior research has suggested that adolescent girls may experience lower levels of selfesteem, experience more fear, and higher levels of anxiety (Block \& Robins, 1993; Bourdon, et al., 1988; Kinsella et al., 2017; Weissman \& Merikangas, 1986). Therefore, girls may be especially reticent. Also, parents are known to be more protective of daughters and this could result in inhibiting courage in girls (Morrongiello \& Hogg, 2004; Valenzuela, 1999). More work is needed to examine whether gender differences exist in courage development among adolescents. This study considered adolescents' gender as an important covariate or moderator of other predictors of courage.

Personality. Prior work has suggested that personality accounts for $21 \%$ of variance in self-reported courage scores among Dutch youth (Muris et al., 2010). Extraversion and openness 
positively related to courage, whereas agreeableness had a negative association (Muris et al., 2010). Therefore, personality dimensions of extraversion, agreeableness, conscientiousness, openness, and neuroticism were considered as covariates.

\section{Present Study}

Predictors of courage development are essential constructs to study because courage may serve as a protective factor among adolescents. Courage could help adolescents build a positive self-concept, increase personal resources, and be more proactive (Hannah et al., 2007). It is important to study predictors of courage so that we can fully understand why some adolescents engage in courageous acts, which can contribute to positive outcomes, such as life satisfaction (Ginerva, et al., 2018).

The first goal of this study is to examine whether various individual characteristics (i.e., self-esteem, emotion regulation) and interpersonal factors, such as attachment to parents and parenting behaviors, predict courage development in a sample of youth in mid-adolescence. The second goal is to conduct exploratory analyses to explore mediation and moderation effects to determine if more complex associations underlie adolescents' level of courage. Various covariates will also be examined, such as socioeconomic status (SES). Although there are no prior publications reporting on how socioeconomic status (SES) is related to courage, as a recent study found that lower SES was associated with greater well-being motives (Gentzler et al., 2021), the current study will test if SES is correlated with adolescents' courage (e.g., adolescents with low SES may have more courage) and include it as a covariate if needed. To date, this study will be the first to explore multiple predictors of general courage in adolescents.

\section{Research Questions and Hypotheses}


Research Question 1: Examine intrapersonal and interpersonal predictors of courage in adolescents.

Hypothesis 1a. Adolescents who reported higher self-esteem were expected to report greater courage.

Hypothesis 1b. The use of more cognitive reappraisal was expected to predict greater courage.

Hypothesis 1c. The use of expressive suppression was expected to predict greater courage.

Hypothesis 1d. Adolescents who report being more anxiously attached to parents were expected to report lower levels of courage.

Hypothesis 1e. Adolescents who report being more avoidantly attached to parents were expected to report higher levels of courage

Hypothesis 1f. Higher levels of autonomy supportive parenting were expected to predict more courage.

Hypothesis 1g. Higher levels of helicopter parenting were expected to predict less courage.

Research Question 2: Conduct exploratory analyses of mechanisms of courage development. For instances where interpersonal indices (parenting or attachment) is correlated with intrapersonal indices (e.g., self-esteem or emotion regulation) and both are correlated with courage, these variables could be examined in mediation models.

Example 1: Adolescents who report experiencing more helicopter parenting were expected to have lower self-esteem, and lower self-esteem should explain why helicopter parenting relates to less courage. 
Example 2: Adolescents who report being more avoidantly attached to parents were expected to use more suppression, and more suppression should explain why avoidantly attached adolescents relates to more courage.

Research Question 3: Conduct exploratory moderation analyses to predict courage in adolescents. Because factors could work together and amplify or dampen main effects, some adolescents may be especially likely to report courage depending on multiple factors.

Example 3: Because some research shows that girls are more impacted by parenting than boys (Bronstein et al., 2007), gender could moderate parenting-courage links in that negative parenting is more strongly related to less courage for girls than boys.

Example 4: Because adolescents with lower self-esteem may be especially impacted by negative parenting (e.g., lower autonomy support and more helicopter parenting; Duineveld et al., 2017; van Ingen et al., 2015), parenting may be more predictive of lower courage for those with low self-esteem.

\section{Method}

\section{Participants}

The total sample included 203 adolescents (51.6\% female), mostly between the ages of 14 and 17 years $\left(43.30 \%\right.$ of age $\left.14 ; M_{a g e}=15.08, S D=.48\right)$. Demographic results indicated that the sample consists of predominantly white adolescents $(88.3 \%)$. The majority of the participants perceived themselves to belong in the mid-range of SES ladder and reported that they had little difficulty paying bills (see Table 2).

In order to estimate the suitable sample size for this project, a power analysis was conducted using G*Power 3.1.9.2 (Faul et al., 2007). A sample of 138 participants was found to be an adequate size to detect a significant medium effect $\left(R^{2}=.15\right)$ at $p<.05$ with $80 \%$ power 
when conducting a multiple linear regression with 5 predictors and 3 covariates. The study was sufficiently powered as the final sample was 203 participants and only 2 covariates included in the models.

\section{Procedure}

The adolescents were part of a larger study that assessed participants at three points across one year: Initial assessment (Time 1), 6 months follow up (Time 2), and 1 year after initial assessment (Time 3). The whole study included adolescents who were recruited via flyers in the community, online advertisements, and in-person recruitment at high schools. Although the whole study collected parental and adolescent self-report data, the present study only uses adolescent self-reported data. Prior to participating in the study, adolescents and parents were provided informational packets. The packets included an overview letter describing the study, a caregiver and adolescent contact information sheet, and an informed consent form for the caregiver to sign for the adolescent to participate in the study. All adolescents gave assent and received parental consent to participate. The Time 1 data were collected in multiple different settings. Data were collected in schools, during home visits, at a research lab, or at a public space. The teens completed Time 1 assessment on paper surveys, either in group settings at schools or individually, with the researcher observing them. After the initial assessment (Time 1), participants completed follow-up surveys (Time 2 and Time 3) in group settings at schools on paper or individually completed surveys on paper at home or online surveys via Survey Monkey. Participants were compensated \$20 (either by giving out cash, an Amazon gift card, or check) after the completion of each survey, and received a $\$ 20$ bonus if they completed all three assessments. 
Data from the current study were obtained at Time 1 and Time 3. Six measures (selfesteem, emotion regulation, parental attachment, parenting behaviors) were from Time 1 and one measure (courage) was from Time 3 . Therefore, the courage measure was assessed roughly a year after the initial assessment, $M_{\text {days }}=395.00, S D=44.13$. For parenting behaviors and attachment, most adolescents reported on both mothers and fathers (or mother-figure and fatherfigures), but a portion of adolescents likely only reported on one parent ( $7.64 \%$ did not report on father-related variables and $4.69 \%$ of adolescents did not report on mother-related variables).

\section{Measures}

Demographics. Adolescents completed a socio-demographic questionnaire regarding their age, gender, name of high school, SES, and race/ethnicity. SES status was reported through two questions. One asked whether the household had difficulties paying bills on a 4-point Likert type scale (1= A great deal to $4=$ None/Not at all). The second asked adolescents to place their families on the MacArthur Scale of Subjective Social Status (SES ladder; Goodman et al., 2001) of where they seem to stand where higher numbers on a 1-10 scale represented the people who had the most money, best education, and respectable jobs, whereas lower numbers described those with less money, little or no education, and less respectable jobs.

Courage. (Appendix A). Adolescents reported on their self-perceived general courage using the Courage Measure (CM, Norton \& Weiss, 2009). The CM is the most widely accepted measure in the field. Within this measure, courage was defined as "persistence or perseverance despite having fear." The measure includes 12 items with a 7-point Likert type scale $(1=$ never to $7=$ always). Eight items are positively worded, and four items are negatively worded. An example of a positively worded item is "I tend to face my fears." An example of a negatively 
worded item is "I will not face something I fear, even if avoiding it will have a negative outcome for me." Higher averaged scores indicate greater courage.

The CM was originally conceptualized as a unidimensional construct. However, Howard and Alipour (2014) acknowledged a bidimensional factor structure across the regular and reverse coding items. With the negatively worded factors removed, the positively worded items displayed a unidimensional construct. Howard and Alipour (2014) found that the removal of the reverse coding items reduced the Cronbach's alpha from .870 to .867 . Other research has further investigated and echoed Howard and Alipour (2014)'s findings (e.g., Cheng \& Huang, 2016; Magnano, et al., 2017). To further evaluate construct validity, a previous study examined the correlation between risk-taking and the CM. Howard and Alipour (2014) reported that the moderate correlation was not strong enough to argue for convergent validity $\left(r_{\text {risk-taking }}=.45\right.$; $p<.01)$. While there are multiple courage measures available, no published research to our knowledge has examined how well those measures correspond with the CM. Although few studies have used these positively and negatively worded items as separate factors, evidence indicates that the removal of the negatively worded items adds little change to internal consistency (Howard \& Alipour, 2014). Because there is also evidence of good internal consistency, the total scale was used in the present study. The total scale items had good reliability for the current study $\alpha=.87$, which was similar to previous work with Dutch youth $(\alpha=.86$; Muris et al., 2010).

Emotion regulation. (Appendix A). The Emotion Regulation Questionnaire for Children and Adolescents (ERQ-CA; Gullone \& Taffe, 2012) is a version of the ERQ (Gross \& John, 2003) that was slightly adapted for youth. The measure includes 10 items to assess emotion regulation (ER) strategies of cognitive reappraisal and expressive suppression. Six items assess 
cognitive reappraisal, and four items assess expressive suppression strategies on a 7-point Likert type scale $(1=$ strongly disagree to $7=$ strongly agree $)$. An example item from cognitive reappraisal is "When I want to feel less bad (e.g. sad, angry, or worried), I think about something different." An example item from expressive suppression is "I control my feelings by not showing them." Higher scores on each scale indicate more utilization of the corresponding emotion regulation strategy. The Cronbach alpha reliability coefficients were .80 for the cognitive reappraisal scale and .71 for the expressive suppression scale.

Self-esteem. (Appendix A). Adolescents reported on their ratings of self-perceived selfesteem via the Rosenberg Self-Esteem scale (Rosenberg, 1965). The measure includes 10 items rated on a 4-point Likert type scale ( $1=$ strongly agree to $4=$ strongly disagree $)$. Example items are "At times, I think I am no good at all" and "On the whole, I am satisfied with myself." There are five reverse scored items. Higher scores indicate higher self-esteem. The scale had good reliability for the current study $(\alpha=.91)$.

Parental attachment. (Appendix A). Adolescents completed The Experiences in Close Relationships - Attachment Orientations (ECR-RS), which assesses their perceived anxious and avoidant attachment with their father and mother (Fraley et al., 2011). The measure includes nine items that respondents rate using a 7-point Likert type scale $(1=$ strongly disagree to $7=$ strongly agree). There is a 6-item avoidance scale and a 3-item anxiety scale. An example item from the attachment-related avoidance dimension is "I usually discuss my problems and concerns with this person," which is reverse scored. An example item from the attachmentrelated anxiety dimension is "I often worry that this person doesn't really care for me." Scores were computed for each dimension and for each interpersonal target (i.e., mother and father). 
The following measure showed good reliability evidence: $\alpha_{\text {avoidance mother }}=.91, \alpha_{\text {avoidance father }}=.90$, $\alpha_{\text {anxious mother }}=.86, \alpha_{\text {anxious father }}=.92$.

Parent autonomy granting. (Appendix A). To assess adolescents' perceived autonomy support from parents, the Parent Behavior Measure was utilized (Peterson et al., 1999). Adolescents answered 10 items for each parent regarding the extent of making decisions regarding friendships, educational goals, career goals, and lifestyles. Items were ranked based on a 4-point Likert scale ( $1=$ strongly agree to $4=$ strongly disagree $)$. A sample item is "This parent (mother) encourages me to help in making decisions about family matters." Higher scores indicate higher levels of autonomy granting. The Parent Behavior Measure has good reliability: $\alpha_{\text {mother }}=.88, \alpha_{\text {father }} .89$.

Helicopter parenting. (Appendix A). Adolescents reported on the degree to which each parent makes important decisions for their teens via the Helicopter Parenting measure (PadillaWalker \& Nelson, 2012). The measure includes five items ranging from 1 (not at all like me/him/her) to 5 (a lot like me/him/her). Example items are "My parent solves any crisis or problem I might have" "My parent makes important decisions for me (e.g., where I live, where I work, what classes I take).” Higher scores indicate more use of helicopter parenting. The Helicopter Parenting measure shows adequate reliability: .70 for adolescent-reported mother helicopter parenting and .78 for father helicopter parenting.

Personality. (Appendix A). To assess adolescents' personality, the Big Five Inventory-2 Extra-Short Form (BFI-2-XS; John \& Soto, 2017) was utilized. Five dimensions of personality (i.e., extraversion, agreeableness, conscientiousness, neuroticism, open-mindedness) were assessed. Each dimension was measured with three items rated on a 5-point Likert type scale (1 = Disagree strongly to $5=$ Agree strongly). An example item for extraversion is "I am someone 
who is dominant, acts as a leader." An example item for agreeableness is "I am compassionate, have a soft heart." An example item for conscientiousness is "I am reliable, can always be counted on." An example item of neuroticism is "I worry a lot." An example item of openmindedness is "I am fascinated by art, music, or literature." Higher scores indicated being higher on each dimension. For the current sample, the reliability scores were .56 for extraversion, .57 for agreeableness, .56 for conscientiousness, .70 for neuroticism, .21 for open-mindedness. Given the unacceptably low reliability for some of the scales, only neuroticism was analyzed in the present study as a potential covariate.

\section{Results}

\section{Preliminary analyses}

Variables were analyzed for missingness with Little's MCAR test. Results indicated that data was not MCAR; $\chi^{2}=251.11, d f=172, p=.00$. Most of the missing data was due to adolescents not reporting on one parent (more often the father) because adolescents may not have two parental figures in their lives. As the missing data pattern was predictable, the observed data was categorized as MAR (Perkins et al., 2018). Only parent-related (e.g., attachment anxious mother and father-related variables) had more than 5\% missingness. Thus, participants with missing data for father-related variables $(n=14-17)$ or mother-related variables $(n=7-13)$ were only excluded for those particular analyses. In general, scale scores were calculated if adolescents answered $80 \%$ of items of the variables that go into each scale.

Attrition analyses were conducted with t-tests and chi-squares to examine whether there were group differences in completion of Time 3 surveys. No significant age and gender differences were found. However, a significant difference was found among races, $x^{2}=21.69$, $p<.001$. While $15.4 \%$ of white adolescents did not complete Time 3, 38\% of other 
races/ethnicities did not complete Time 3. No significant differences were found for adolescent intrapersonal variables (self-esteem, emotion regulation skills) and interpersonal variables (attachment anxiety and avoidant dimensions, autonomy support) except for helicopter parenting. Adolescents who did not complete Time 3 reported higher scores of helicopter parenting for mothers and fathers at Time $1\left(M_{\text {mother }}=3.27, S D=0.96 ; M_{\text {father }}=2.68, S D=1.12\right)$ than did those who completed Time $3\left(M_{\text {mother }}=2.85, S D=0.86 ; M_{\text {father }}=2.34, S D=0.94\right), t(282)_{H P-\text { mother }}=-3.06$, $p<.001 ; t(271)_{H P-\text { father }}=-2.26, p=.01$.

Univariate and bivariate normality issues were also analyzed. The measures of autonomy support for mother and father were negatively skewed. The measures of attachment anxious mother and father were positively skewed. Both scores of autonomy support for mother and father were reflected prior to computing square root transformations and reflected once more for ease of interpretation. Log transformations were computed to fix the positive skew for attachment anxious variables. The log transformations did not fix the skewness entirely (e.g., anxious attachment with mothers' $Z_{\text {skewness }}=3.9$ ). Additionally, boxplots were used to identify univariate outliers. Several outliers were identified among the variables of autonomy support mother, autonomy support father, and courage. Five outliers were found for autonomy support father. To reduce bias, the five outliers were winsorized and replaced with the next highest score of 1.67 at $.20 S D$ (Kwak \& Kim, 2017). Two outliers were found for autonomy support mother and were replaced with the next highest score of 1.67 at .20 SD (Kwak \& Kim, 2017). Four outliers were found for courage and were winsorized to 2.08 at 1.01 (Kwak \& Kim, 2017). Scatterplots were assessed to check linearity. All variables appeared to have a linear relationship. Multivariate issues were further assessed as there still exists a possibility of having multivariate outliers after assessing univariate outliers. Mahalanobis distance was calculated with 
15 variables (gender, difficulty paying bills, SES ladder, self-esteem, cognitive reappraisal, expressive suppression, autonomy support mother and dad, helicopter parenting mom and dad, attachment anxious mom and dad, attachment avoidant mom and dad, and courage) to identify multivariate outliers. Three multivariate outliers were determined by mahalanobis distance values which are more than the critical value of $\chi^{2}=36.12, d f=14, p=.001$ (Tabachnick $\&$ Fidell, 2007). These three cases were excluded from the final sample, which resulted the final sample to be 203 .

Diagnostic checks for multivariate issues were conducted by examining standardized residuals, P-P plots, and scatterplot of regression standardized predicted value and regression studentized residual. There was an overall good cloud with no apparent shape or direction. Some points seemed to have moderate levels of leverage, but low levels of influence and discrepancy. To further identify influential points, the scatterplot between cook's distance and centered leverage value was computed. No influential points were identified. Collinearity issues were assessed with tolerance and VIF values. Evidence of multicollinearity issues were not identified because tolerance values were all greater than .20 and VIF values were all less than 4.0 (Schroeder, 1990).

Demographics and covariates. Demographic information (e.g., gender, age, race/ethnicity) are presented in Table 1, variables' means and standard deviations are presented in Table 2, and bivariate correlations are presented in Table 3.

In terms of the variables that were significantly correlated with courage, SES, selfesteem, and reappraisal were all positively correlated with courage. In addition, adolescents who received more autonomy support from mothers and fathers reported greater courage, and adolescents who reported more helicopter parenting by mothers reported less courage. 
Independent samples t-test was completed to test for gender and race differences. Males reported more courage than girls, $t(201)=-2.75, p<.001$. Adolescents' race was dichotomized into white and other ethnicities. No significant differences for courage and other variables were found between the dichotomized races, $t(200)=-.90, p=.46$. As previous research (Muris et al., 2009) has found associations between personality and courage, personality variables were included as covariates. Neuroticism was negatively correlated with courage, $\beta=-.26, p<.001$. Openness $(\beta=.16, p=.02)$ and extraversion $(\beta=.23, p<.001)$ were positively associated with adolescent courage. However, because literature suggest that Cronbach alpha values should be at least .70 to be acceptable (Bresciani et al. 2019), it was concluded that the openness (alpha =.21) and extraversion (alpha $=.56$ ) did not have adequate reliability. Therefore, only neuroticism was included for further analyses. Gender and SES-ladder were included as covariates in all subsequent analyses, and analyses were run with and without neuroticism (see Appendixes B for results with neuroticism).

\section{Primary Analyses}

Examining main effects. Eight hierarchical linear regression models were conducted to examine the unique contribution of adolescents' interpersonal and intrapersonal factors in explaining courage. The standardized coefficients are presented in Tables 4 and 5. In the first step of all eight models, courage was regressed onto gender and SES ladder (covariates). Each interpersonal and interpersonal factor was entered into the equation at step two. First, the covariates significantly predicted courage scores in the first step of all 8 models, accounting for 5-6\% of the variance. In most models (e.g., self-esteem, autonomy support, helicopter parenting, and emotion regulation skills), both SES ladder and gender significantly predicted courage in the first step of each model, indicating that males and those higher on SES reported greater courage. 
In the models with mother and father attachment styles (model 1 and 4), gender was not a significant predictor in the first step, suggesting that only adolescents higher on the SES status reported greater courage (see Table 4).

In the second step of the models with mother-related variables, adolescents' avoidant and anxious attachment to mothers were not significant predictors of courage above and beyond gender and SES ladder. In the second step of the autonomy support model, autonomy support of mothers accounted for an additional $6 \%$ of the variance explained in courage, suggesting that autonomy support of mothers significantly predicted courage over and above the covariates (see Table 4). In the third model, mothers' helicopter parenting added an additional $2.2 \%$ of additional of the variance explained in courage. Greater helicopter parenting of mothers predicted significantly lower courage scores, $t(187)=-2.13, p=.03$ (see Table 4 ).

In the second step of father-related variables, results indicated that adolescents' avoidant and anxious attachment with fathers were not significant predictors of courage above and beyond the covariates, $t(177)_{\text {Avoidant }- \text { Father }}=-.94, p=.35, t(177)$ Anxious-Father $=.04, p=.97$ (standardized beta values are reported in Table 4). In the fifth model, fathers' autonomy support explained an additional $2.3 \%$ of the variance in courage, $t(177)=2.12, p=.04$, suggesting that autonomy support of fathers significantly predicted courage above and beyond the covariates. In the sixth model, fathers' helicopter parenting was not a significant predictor of courage, $t(180)=.28$, $p=.78$. The standardized regression coefficients for all interpersonal variables (e.g., parentingrelated) are reported in Table 4.

For the final two models with intra-personal variables, self-esteem accounted for $10.2 \%$ of additional variance of courage, $t(185)=4.77, p<.001$, suggesting that self-esteem is a significant predictor of courage over and above gender and SES ladder. In the eighth model, 
emotion regulation skills (e.g., cognitive reappraisal and expressive suppression) accounted for an additional $5.3 \%$ of the variance of courage. Reappraisal positively predicted courage, whereas suppression was not significantly related to courage (see Table 5).

Exploratory mediational analyses. To further understand the mechanisms of courage, mediation analyses were conducted with PROCESS (Hayes, 2013). The same covariates (gender and SES ladder) were included. Exploration of mechanisms were guided by theory (e.g., parenting qualities contribute to children's psychological development; Kagan, 1999) as recommended by Rucker et al (2011). Therefore, models examined whether adolescents' interpersonal relationships affected adolescents' intrapersonal factors, which in turn potentially affect courage. Eight models were found to be significant.

The first set of models with autonomy support with mothers and self-esteem (and covariates of gender and SES) showed that these variables accounted for $21 \%$ of the variance as a whole, $F(4,180)=11.77, p<.001$. Autonomy support of mothers related with self-esteem, and self-esteem predicted courage. Mothers' autonomy support was significantly and indirectly related to courage through self-esteem. Furthermore, a significant total direct effect from autonomy support with mothers to courage was found (see Figure 1).

Likewise, the model with autonomy support of fathers, self-esteem, and covariates indicated that these variables accounted for $19 \%$ of the variance in courage, $F(4,172)=9.85$, $p<.001$. Autonomy support of fathers linked with self-esteem, and self-esteem predicted courage. Thus, the indirect effect was significant, such that fathers' autonomy support indirectly associated with courage through self-esteem. However, the direct effect of father's autonomy support on courage was not significant (see Figure 2). 
The third set of models with attachment-anxiety with mothers, self-esteem, and covariates, demonstrated that these variables accounted for $17 \%$ of the variance as a whole, $F(4,176)=9.29$. Greater scores on the attachment anxiety dimension of mothers were negatively and significantly related to self-esteem, suggesting that adolescents higher on the attachment anxiety dimension had lower self-esteem. Self-esteem significantly predicted greater courage. Additionally, a significant negative indirect effect was found, suggesting adolescents who scored high on attachment-anxiety with mothers had lower self-esteem, which associated with less courage. The direct effect between anxious attachment to mothers and courage was not significant ( $p=.28$; see Figure 3).

Similarly, the fourth set of models with attachment-anxiety with fathers and self-esteem (as well as covariates) as a whole accounted for $17 \%$ of the variance in courage, $F(4,173)=8.93$, $p<.001$. Greater scores on attachment-anxiety with fathers significantly related lower selfesteem, and self-esteem positively predicted courage. A significant negative indirect effect was found, suggesting that adolescents higher on the attachment anxiety dimension had lower selfesteem, which associated with less courage. The direct effect of attachment-anxiety with fathers to courage was not significant ( $p=.17$, see Figure 4$)$.

The fifth set of models, which included avoidant attachment with mothers, self-esteem, and covariates, as a whole accounted for $17 \%$ of variance in courage, $F(4,181)=9.16, p<.001$. Greater scores on avoidant attachment with mothers significantly associated with lower selfesteem, and self-esteem significantly related with courage. Thus, the indirect effect was negative and significant, suggesting that adolescents higher on the attachment avoidant dimension with mothers had lower self-esteem, which in turn related with less courage. The direct effect of attachment-avoidant with mothers was not significant $(p=.55$, see Figure 5). 
The sixth set of models that consisted with avoidant attachment with fathers and selfesteem (and covariates), as a whole, accounted for $16 \%$ of the variance in courage, $F(4,174)=8.58, p<.001$. Greater scores on avoidant attachment with fathers significantly related with lower self-esteem, and self-esteem positively related with courage. The indirect effect was significant, such that adolescents who reported being higher on the attachment avoidant dimension with fathers had lower self-esteem, which in turn associated with less courage. However, the direct effect of avoidant attachment with fathers on courage was not significant $(\mathrm{p}=.55$, see Figure 6).

The seventh set of models, including avoidant attachment with mothers and cognitive reappraisal (and covariates), as a whole, explained $10 \%$ of the variance in courage, $F(4,184)=4.86, p<.001$. Avoidant attachment with mothers was negatively and significantly related with cognitive reappraisal, suggesting greater avoidant attachment of mothers linked to less utilization of cognitive reappraisal. Cognitive reappraisal significantly and positively related with courage. In addition, the indirect effect was significant: adolescents higher on the attachment avoidant dimension with mothers engaged in less cognitive reappraisal, which in turn predicted less courage. The direct effect of attachment avoidant with mothers on courage was not significant ( $p=.88$, see Figure 7).

The last model with helicopter parenting and cognitive reappraisal (and covariates), as a whole, accounted for $13 \%$ of the variance in courage, $F(4,185)=7.20, p<.001$. Helicopter parenting positively and significantly related with cognitive reappraisal, and cognitive reappraisal significantly related with greater courage. The indirect effect was positive and significant, suggesting that adolescents who scored higher in maternal helicopter parenting used more reappraisal, which predicted greater courage. However, a suppression effect was found 
because the negative direct effect was significant. The negative direct effect suggests that maternal helicopter parenting may not be beneficial for courage. A similar pattern of a suppression effect is also found in personality-health research, in which the direct effect between neuroticism and health behavior is unhealthy but beneficial through vigilance (e.g., healthy neuroticism; Weston \& Jackson, 2018).

Exploratory moderation analyses. Given how little is known about courage, moderation analyses were also conducted. Based on one study finding that girls' level of moral courage was more related to parenting than boys' moral courage (Bronstein et al., 2007), moderation models tested whether the association between negative parenting of both parents (lower autonomy support and more helicopter parenting) and courage was different for males and females. However, the interaction terms between parents' autonomy support and helicopter parenting and gender were not significant.

Additionally, as prior research has found that youth with lower self-esteem may be particularly impacted by negative parenting (Duineveld et al., 2017), a model was conducted to test whether the association between negative parenting and courage varied as a function of selfesteem. Results indicated that there was no significant Self-esteem X Negative Parenting (i.e., lower autonomy support and greater helicopter parenting of both parent) interactions.

\section{Discussion}

This study provides new evidence of predictors of courage among adolescents. The current study assessed whether interpersonal (i.e., parenting behavior, attachment) and intrapersonal (i.e., self-esteem, emotion regulation skills) variables predict courage, and the extent to which intrapersonal factors mediated association between interpersonal factors and courage. Empirically exploring the antecedents of courage is important as majority of the 
literature on courage is theoretical. Although one other study examined predictors of adolescent moral courage (Bronstein et al., 2007), the present study, to date, is the first to empirically assess predictors of general courage in adolescents, as well as the first to explore multiple predictors and exploratory mechanisms in the same study.

\section{Interpersonal Predictors of Courage}

The findings supported some of the hypotheses of how interpersonal factors relating to parenting predicted courage. First, with autonomy support of mothers and fathers, findings were supported in expected ways. More autonomy support of parents associated with greater courage. Although no prior work examined the association between autonomy support of parents and general courage, one study has examined autonomy support (i.e., aware parenting) and its relation to moral courage (Bronstein et al., 2007). Bronstein et al. found that aware parenting and boys' moral courage was unrelated, while a positive association was found for adolescent girls. Their findings are consistent with the present study's finding of autonomy support correlating with girls' courage, but inconsistent as autonomy support also significantly related with boys' courage in the present study (given gender was not a significant moderator). Theoretically, autonomy support is expected to foster self-initiating behavior because parents support their child's decisions (Grolnick \& Ryan, 1989). In addition, empirical evidence shows that parental autonomy related with self-esteem (Robbins, 1994), which supports the present study's finding that autonomy support led to greater courage through self-esteem. The utilization of a broader measure of courage may explain why the association was found for both boys and girls in the present study. Gender differences may have been found in Bronstein et al. because relational factors may be more salient motivators for women as Pury et al. (2007) speculate. Girls may have engaged in greater moral courage in circumstances of encountering mistreatment of others 
(Detert \& Bruno, 2017). Future studies could explore whether gender predicts types of courage with multiple measures of different courage in a single study.

As expected, more helicopter parenting of mothers associated with less courage. The negative association between mothers' helicopter parenting and courage may be due to adolescents' decreased autonomy, as found in emerging adult samples (Schiffrin et al., 2019). However, findings did not support the hypothesis for helicopter parenting of fathers and courage. The unrelated relationship between paternal helicopter parenting and courage is surprising. Past research has identified patterns of fathers' helicopter parenting relating to greater levels of distress than mothers' helicopter parenting (Love et al., 2019; Rousseau \& Scharf, 2015). It might be that paternal helicopter parenting alone is less relevant to courage as evidence suggests that parenting practices of mother and fathers differently impact child outcomes. Some researchers have speculated that participants may only refer to mothers when asked to consider helicopter parenting (Schiffrin et al., 2019). The limited work on paternal helicopter parenting urge for a greater need to explore the role of parental gender in relation to helicopter parenting and psychosocial outcomes. Additionally, because most studies on helicopter parenting were conducted with emerging adult samples, more work should examine whether maternal and paternal helicopter parenting differently impact associated outcomes among adolescent samples. Nevertheless, this study's finding of maternal helicopter parenting relating with less courage is novel and can be applied to help design parenting programs to facilitate adolescents' positive development.

Findings regarding attachment dimensions were not consistent with what was hypothesized. Avoidant and anxious attachment were not directly associated with courage but were indirectly related to courage through interpersonal factors (i.e., self-esteem, cognitive 
reappraisal). Specifically, adolescents higher on the avoidant attachment dimension with parents, had lower self-esteem, which in turn related with less courage. Likewise, adolescents higher on the anxious attachment dimension with parents reported lower self-esteem, which related with less courage. Teens who reported being higher on avoidant-attachment with mothers engaged in less cognitive reappraisal, which led to less courage. As being higher on the avoidant dimension suggests that they are less likely to have a secure base and explore (Aspelmeier \& Kerns, 2003), adolescents may be less confident (Mikulincer et al., 2001) to take risks required in courageous behaviors. Furthermore, Detert and Bruno (2017) propose that courage is more intended to benefit others (rather than the self). Because insecurely attached adolescents are less likely to feel secure that others are trustworthy and be empathetic (Mikulincer et al., 2001), it may be harder for avoidantly and anxiously attached individuals to engage in courageous acts that are beneficial for others. Additionally, research suggests that adolescents higher on attachment anxious dimension are more likely to engage in negative cognitive processes (Gamble \& Roberts, 2005), which could explain less utilization of cognitive reappraisal as found among adults (Read et al., 2018). Thus, avoidantly and anxiously attached individuals may not feel worthy of seeking support due to less self-esteem or be inspired to take action due to the lack of supportive attachment figures (Howard \& Medway, 2004).

\section{Intrapersonal Predictors of Courage}

The hypothesis that self-esteem would positively predict courage was supported. Although research on self-esteem and courage is limited, self-esteem was proposed theoretically to promote courage by further influencing positive states (i.e., self-efficacy, hope, positive emotions; Hannah et al., 2007). A study with adolescents found a positive association between 
self-esteem and moral courage (Bronstein et al., 2007). This study's finding extends the literature by suggesting that self-esteem may be a predictor of general courage among adolescents.

As expected, greater cognitive reappraisal was associated with greater courage. The novel finding between cognitive reappraisal and courage may be explained by cognitive reappraisal aiding in downregulating negative affect (Opitz et al., 2009). Perhaps adolescents who engage in more cognitive reappraisal may be more effective in reducing negative affect, which enable them to overcome risk, be optimistic about outcomes, and demonstrate greater courage. The hypothesis of expressive suppression positively predicting courage was not supported, as results suggested that they were unrelated. Although the unexpected result is difficult to comprehend, perhaps suppression does not matter because suppression is cognitively taxing as of itself, as it does not reduce the subjective experience of negative affect (Butler et al., 2003). Hiding emotional displays may be overwhelming which could explain why there was no relationship between the expression suppression and courage. It may be worth examining in future studies whether emotion regulation predicts particular types of courage (e.g., physical) but not others.

\section{Exploring Mediating and Moderated Paths}

The current study contributes to the literature to be the first to explore mediation mechanisms of courage. Results suggest that self-esteem mediates the positive association between mothers and fathers' autonomy support and courage. The findings are consistent with work from a 1-year longitudinal study that suggests parental autonomy support is related to greater self-esteem across time (Van Petegem et al., 2018). Findings of this study extends the literature by suggesting positive self-concepts fostered through autonomy support of parents contribute to greater courage. 
The pathway between anxious attachment of both parents and adolescent courage was found to be indirectly linked through self-esteem. Specifically, adolescents higher on the anxious dimension of mothers had less self-esteem and less courage. Likewise, those more anxiously attached to fathers had less self-esteem and less courage. These findings are consistent with prior work that suggests that anxiously attached adolescents are more likely to not have protective buffers of self-esteem (Dan et al., 2014; Lee \& Hankin, 2009). A strength of this study is that adolescents reported on both mothers and fathers. Such findings contribute to the literature as it demonstrates how anxious attachment of both parents is associated with adolescent general courage through cognitive factors such as self-esteem.

Similarly, the pathway between avoidant attachment of both parents and courage was mediated through self-esteem in that the more avoidantly attached individuals had lower selfesteem and less courage. These findings suggest that avoidantly attached adolescents may not feel the sense of self-assurance due to the lack of secure base and supportive parents (Aspelmeier \& Kerns, 2003), which may further discourage a positive view of oneself. These adolescents may not be confident that they have the ability to overcome risks.

An indirect path was also found between avoidant attachment with mothers and courage through lower levels of cognitive reappraisal. Adolescents who were more avoidantly attached to their mothers utilized less cognitive reappraisal, which associated with less courage. These findings are interesting as they are inconsistent with previous research that suggests the links between attachment avoidance and cognitive reappraisal to be unrelated (Gross \& John, 2003). This relationship may represent a general trend of individuals higher on the avoidant dimension are more likely to avoid avoiding or diverting from negative affect (Mikulincer \& Shaver, 2018). Additionally, less cognitive reappraisal has been found to be related with negative self-concepts 
(Hseih \& Stright, 2012) Taken together, perhaps adolescents higher on the avoidant attachment dimension of mothers have difficulty engaging in productive reappraisal because they have learned through their interaction patterns to have low expectations form relationship connections (Mikulincer et al., 2001; Spielmann et al., 2013) that may further lead to low self-esteem. Such tendencies may explain why more avoidant attachment is associated with less cognitive reappraisal which then relates to less courage. It is important to note that no indirect link of cognitive reappraisal was found between avoidant attachment to fathers and courage. The absence of such finding may be due to attachment patterns to mothers and fathers contributing to different domains of child development (Bacro, 2011). Research has shown that mothers sometimes may play a greater role in their child's emotional development (Klimes-Dougan et al., 2007) and that adolescents are more likely to turn to their mothers for support (Markiewisc et al., 2006).

In general, helicopter parenting of mothers directly related to less courage, which suggests that maternal helicopter parenting was detriment to courage. However, an exception was found when examining the indirect effect through cognitive reappraisal. A suppression effect suggested that maternal helicopter parenting was linked with greater cognitive reappraisal, which then predicted greater courage. Such effect is a novel finding, and it contributes to literature showing that helicopter parenting is sometimes related to negative outcomes (e.g., less autonomous children; Schiffrin et al., 2014) but could also be related to positive outcomes, like courage, as Padilla-Walker and Nelson (2012) explain helicopter parenting includes positive behavior (e.g., providing emotional support or motivation to achieve life goals). The supportive mothers who engage in helicopter parenting behavior may help their children to reinterpret risks to help achieve life goals, which in turn may lead to greater courage. The absence of the fathers' 
finding is not clearly understood as Klein and Pierce (2009) has found that fathers' helicopter parenting contributed to more college adjustment difficulties of emerging adults than mothers. Overall, this finding contributes to the literature as it explains how helicopter parenting of mothers could relate with both negative and positive outcomes, such as maternal helicopter parenting directly leading to less courage, but also encouraging courage through greater cognitive reappraisal.

In this study, potential moderated effects were also explored given that factors such as gender and self-esteem could moderate the relationship between negative parenting (lower autonomy support and more helicopter parenting) and courage. However, all interaction terms were not significant. For example, the expected gender differences in courage were not found among the association between lower autonomy support and courage. Additionally, greater helicopter parenting of both parents was not associated with courage at different levels of selfesteem. It is surprising to see that these moderated findings did not come out as expected, which suggests that factors such as negative parenting are operating in the same way for boys and girls, as well as for those with low or high self-esteem. Interestingly, this main effect for parenting seems to be similar to some patterns in the literature. Bean and Northrup (2009) did not find any significant gender differences among the association between parenting behavior (i.e., psychological control, psychological autonomy, and acceptance) and self-esteem among Latino adolescents, or among Irish adolescents (Kristjánsson \& Sigfúsdóttir, 2009). However, in studies with college students, gender differences were found, such that girls' well-being were more impacted by helicopter parenting than boys, and that greater autonomy support for boys related to less dysphoria (Kouros et al., 2017). Given the conflicting evidence in different developmental 
period, future work should further examine whether other moderating effects (e.g., age) occur in relation to parenting and courage.

\section{Limitations and Future Directions}

Despite the contributions of the current study, this study was not without limitations. First, the sample consisted primarily of white adolescents. Although, cross-ethnic/cultural consistencies may exist as courage is valued across cultures (Lopez et al., 2010), findings may not be generalized to other ethnic groups or cultures. For example, some cultures (e.g., Eastern) with interdependent construals may view being reticent as courageous rather than actively taking a stand (Markus \& Kitayma, 1991). Interestingly, a previous study with Chinese adults found an unexpected greater emphasis of individually-oriented courage rather than socially oriented courage through qualitative analyses (Cheng \& Huang, 2016). Given that their study was the first to examine the construct of courage with non-western individuals, additional investigations should examine whether cultural-specific factors of courage exist among different ethnicities and cultures.

Additionally, as courage is valued in the society, adolescents may over-report courage due to social desirability (Krumpal, 2013). Similarly, self-reported surveys of other measured constructs are limited because they are subjective and increase the likelihood of participant bias (Latkin, 2016), which may further affect the validity of the findings. Although the surveys included validity checks, the current study lacks the ability to test effects of social desirability. Rather than only implementing self-report measures, future studies should incorporate multiple informants of courage (i.e., peers, parents, teachers) as well as observational data.

The courage measure used in this study was a measure of general courage that did not define various types of courage (moral, physical, social, etc.). While the lack of empirical 
research on general courage has prompted the exploratory examination of this study, the reliance on an unspecific courage measure (Norton \& Weiss, 2009) may have impacted the results of the study. For instance, the wordings of the Courage measure may have led adolescents to not consider relatively abstract risks related to psychological (e.g., addressing phobias; Putman, 1997) or existential courage (e.g., searching for meaning in life; Maddie, 2004). For example, items such as "I will do things even though they seem to be dangerous" or "Even if something scares me, I will not back down" could prompt adolescents to consider more concrete risks. In addition, findings of the study may not be generalizable to other types of courage because the utilized courage measure may not assess narrow dimensions of different types of courage.

Because all predictors were measured at Time 1 and courage was only measured at Time 3, interpretation of the findings should be heeded with caution as the process of courage may have not unfolded over time. For example, the lack of additional measurements of courage at earlier timepoints make it difficult to argue that courage increased over time. Because courage was not measured at Time 1 , it is impossible to argue that courage levels have changed over time. To our knowledge, only a single study has investigated age differences in courage (three age groups: 5-6 years, 8-9 years, and 11-12 years old; Szagun,1992). However, a recent study suggests that there is a positive linear relationship between age and positive risk taking (12-25 year olds, $M_{a g e}=18.99 S D=3.37$; Fryt $\&$ Sczygiet, 2021), which may imply that courage could also increase over time. Thus, more work is needed to understand how courage develops over time. Future work should have at least three measurements of each predictor and outcome to reliably estimate the development of courage (Singer \& Willett, 2003). This study also lacks the ability to tease bidirectional and causal effects because the temporal relationship could not be established due to the utilization of non-experimental methods (Hung et al., 2017). Prior 
literature has not examined bidirectional effects between courage and all predictors (e.g., whether courage predicts greater self-esteem). Future work should incorporate cross-lagged models (Erhart et al., 2017) or assess conduct observational research to demonstrate directional and causal effects. Despite the limitation, it is expected that this study will fill the gap of existing literature by providing a more robust explanation of how courage develops in youth.

Although the current study explored multiple predictors in a single study, additional factors may also contribute to adolescent courage development. In their theoretical model of courage, Hannah and colleagues (2007) posited factors such as social support, peer relationships, and motivations may contribute to courage. Given that adolescents are in a developmental period of when peers become relatively more important (Sanders, 2013), future work should include factors such as peers and social support to explore its relationship with courage. In addition, future studies can also examine types of courage to better understand if common types of courage exist in general or during/across certain developmental periods, incorporating qualitative methods may be beneficial for this process.

In addition, as several models were tested in the current study, there is a possibility to have Type 1 errors. (Shaffer, 1995). Future studies should utilize analysis methods that could combine multiple tests into one (e.g., Bonferroni correction or False Discovery Rate; Andrade, 2019; Benjamin \& Hochberg, 1995) to minimize Type 1 errors. Lastly, courage research will also benefit from examining outcomes related to courage.

\section{Conclusion}

As adolescence is a challenging time of encountering risks (e.g., academic, creating and maintaining relationships, significant life changes), it is important to understand factors and the processes that can help offset the adversities. This study was the first to empirically explore the 
antecedents of general courage in an adolescent sample. The current findings advance the understanding on how interpersonal and intrapersonal factors relate to general courage among adolescents. Findings indicate that contributing factors of parenting behaviors (autonomy support, attachment, helicopter parenting) may encourage adolescent courage through selfesteem and cognitive reappraisal. Future interventions may target parenting practices and emotion regulation skills, such as encouraging autonomy support and cognitive reappraisal to promote courage among adolescents, and especially among those with high anxiety (Muris et al., 2009). 


\section{References}

Adams, R. M. (2006). A theory of virtue: Excellence in being for the good. Clarendon Press.

Ainsworth, M. D. S., Blehar, M. C., Waters, E., \& Wall, S. (1978). Patterns of attachment: A psychological study of the Strange Situation. Hillsdale, NJ: Erlbaum.

Andrade, C. (2019). Multiple Testing and Protection Against a Type 1 (False Positive) Error Using the Bonferroni and Hochberg Corrections. Indian Journal of Psychological Medicine, 41(1), 99-100. https://doi.org/10.4103/IJPSYM.IJPSYM_499_18

Aspelmeier, J. E., \& Ken, K. A. (2003). Love and school: Attachment/exploration dynamics in college. Journal of Social and Personal Relationships, 20(1), 5-30.

doi:10.1177/0265407503020001185

Bacro, F. (2011). Perceived Attachment Security to Father, Academic Self-Concept and School Performance in Language Mastery. Journal of Child and Family Studies, 21. https://doi.org/10.1007/s10826-011-9561-1

Barber, B. (1996). Parental Psychological Control: Revisiting a Neglected Construct. Child Development, 67, 3296-3319. doi:10.2307/1131780

Bartholomew, K., \& Horowitz, L. M. (1991). Attachment styles among young adults: A test of a four-category model. Journal of Personality and Social Psychology, 61, 226-244. https://doi.org/10.1037/0022-3514.61.2.226

Bean, R. A., \& Northrup, J. C. (2009). Parental Psychological Control, Psychological Autonomy, and Acceptance as Predictors of Self-Esteem in Latino Adolescents. Journal of Family Issues, 30(11), 1486-1504. https://doi.org/10.1177/0192513X09339149

Benjamini, Y., \& Hochberg, Y. (1995). Controlling the False Discovery Rate: A Practical and Powerful Approach to Multiple Testing. Journal of the Royal Statistical Society. Series B (Methodological), 57(1), 289-300. 
Betts, J., Gullone, E., \& Allen, J. S. (2009). An examination of emotion regulation, temperament, and parenting style as potential predictors of adolescent depression risk status: a correlational study. The British Journal of Developmental Psychology, 27( 2), 473-485. https://doi.org/10.1348/026151008x314900

Blascovich, J., \& Tomaka, J. (1991). Measures of self-esteem. In J. P. Robinson, P. R. Shaver \& L. S. Wrightsman (Eds.)., Measures of Personality and Social Psychological Attitudes (pp 115-160). https://doi.org/10.1016/b978-0-12-590241-0.50008-3

Block, J., \& Robins, R. W. (1993). A longitudinal study of consistency and change in self-esteem from early adolescence to early adulthood. Child Development, 64, 909-923. https://doi.org/10.2307/1131226

Bonanno, G. A., Papa, A., Lalande, K., Westphal, M., \& Coifman, K. (2004). The importance of being flexible. Psychological Science, 15, 482-487. https://doi.org/10.1111/j.09567976.2004.00705.x

Bourdon, K. H., Boyd, J. H., Rae, D. S., Burns, B. J., Thompson, J. W., \& Locke, B. Z. (1988). Gender differences in phobias: Results of the ECA community survey. Journal of Anxiety Disorders, 2, 227-241. https://doi.org/10.1016/0887-6185(88)90004-7

Bowlby, J. (1969). Attachment and loss, Vol. 1: Attachment. New York: Basic Books Bowlby, J. (1982). Attachment and loss: Retrospect and prospect. American Journal of Orthopsychiatry, 52, 664-678. https://doi.org/10.1111/j.1939-0025.1982.tb01456.x

Brenning, K., Soenens, B., Van Petegem, S., \& Vansteenkiste, M. (2015). Perceived maternal autonomy support and early adolescent emotion regulation: A longitudinal study. Social Development, 24, 561-578. https://doi.org/10.1111/sode.12107 
Brennan, K.A., Clark, C.L., \& Shaver, P.R. (1998). Self-Report Measurement of Adult Attachment: An Integrative Overview. In: Simpson, J.A. and Rholes, W.S. (Eds.), Attachment Theory and Close Relationships, Guilford Press (pp.46-76). New York.

Bresciani, M., Oakleaf, M., Kolkhorst, F., Nebeker, C., Barlow, J., Duncan, K., \& Hickmott, J. (2019). Examining Design and Inter-Rater Reliability of a Rubric Measuring Research Quality across Multiple Disciplines. Practical Assessment, Research, and Evaluation, 14(1). https://doi.org/10.7275/1w3h-7k62

Bronstein, P., Fox, B. J., Kamon, J. L., \& Knolls, M. L. (2007). Parenting and gender as predictors of moral courage in late adolescence: A longitudinal study. Sex Roles, 56(910), 661-674. https://doi.org/10.1007/s11199-007-9182-8

Butler, E., Egloff, B., Wilhelm, F., Smith, N., Erickson, E., \& Gross, J. (2003). The Social Consequences of Expressive Suppression. Emotion (Washington, D.C.), 3, 48-67. https://doi.org/10.1037/1528-3542.3.1.48

Cheng, C., \& Huang, X. (2016). An exploration of courage in Chinese individuals. The Journal of Positive Psychology, 12(2), 141-150. https://doi.org/10.1080/17439760.2016.1163406

Choi, S., Kim, D., Choi, J., Ahn, H., Choi, E., Song, W., Kim, S., \& Youn, H. (2015).

Comparison of risk and protective factors associated with smartphone addiction and internet addiction. Journal of Behavioral Addictions, 4(4), 308-314. https://doi.org/10.1556/2006.4.2015.043

Cline, F., \& Fay, J. (1990). Parenting with love and logic: teaching children responsibility. Colorado Springs, CO: Piñon Press.

Coopersmith, S. (1967). The antecedents of self-esteem. San Francisco: W. H. Freeman and Company. 
Cox, D., Hallam, R., O'Connor, K., \& Rachman, S. (1983). An experimental analysis of fearlessness and courage. British Journal of Psychology, 74(1), 107-117. https://doi.org/10.1111/j.2044-8295.1983.tb01847.x

Dahlsgaard, K., Peterson, C., \& Seligman, M. E. (2005). Shared virtue: The convergence of valued human strengths across culture and history. Review of General Psychology, 9(3), 203-213. https://doi.org/10.1037/1089-2680.9.3.203

Dan, O., Bar Ilan, O., \& Kurman, J. (2014). Attachment, self-esteem and test anxiety in adolescence and early adulthood. Educational Psychology, 34(6), 659-673. https://doi.org/10.1080/01443410.2013.814191

Darlow, V., Norvilitis, J. M., \& Schuetze, P. (2017). The relationship between helicopter parenting and adjustment to college. Journal of Child and Family Studies, 26(8), 22912298. https://doi.org/10.1007/s10826-017-0751-3

Doyle, A. B., Lawford, H., \& Markiewicz, D. (2009). Attachment style with mother, father, best friend, and romantic partner during adolescence. Journal of Research on Adolescence, 19(4), 690-714. https://doi.org/10.1111/j.1532-7795.2009.00617.x

Duell, N., \& Steinberg, L. (2021). Adolescents take positive risks, too. Developmental Review, 62, 100984.https://doi.org/10.1016/j.dr.2021.100984

Duell, N., \& Steinberg, L. (2019). Positive Risk Taking in Adolescence. Child Development Perspectives, 13(1), 48-52. https://doi.org/10.1111/cdep.12310

Duineveld, J. J., Parker, P. D., Ryan, R. M., Ciarrochi, J., \& Salmela-Aro, K. (2017). The link between perceived maternal and paternal autonomy support and adolescent well-being across three major educational transitions. Developmental Psychology, 53(10), 19781994. https://doi.org/10.1037/dev0000364 
Erhart, R., Mahlendorf, M., Reimer, M., \& Schäffer, U. (2017). Theorizing and testing bidirectional effects: The relationship between strategy formation and involvement of controllers. Accounting, Organizations and Society, 61. https://doi.org/10.1016/j.aos.2017.07.004

Faul, F., Erdfelder, E., Lang, A., \& Buchner, A. (2007). G*Power 3: A flexible statistical power analysis program for the social, behavioral, and biomedical sciences. Behavior Research Methods, 39(2), 175-191. https://doi.org/10.3758/bf03193146

Feeney, B. C., Cassidy, J., \& Ramos-Marcuse, F. (2008). The generalization of attachment representations to new social situations: Predicting behavior during initial interactions with strangers. Journal of Personality and Social Psychology, 95(6), 1481-1498. https://doi.org/10.1037/a0012635

Finfgeld, D. L. (1999). Courage as a process of pushing beyond the struggle. Qualitative Health Research, 9(6), 803-814. https://doi.org/10.1177/104973299129122298

Fingerman, K. L., Cheng, Y., Wesselmann, E. D., Zarit, S., Furstenberg, F., \& Birditt, K. S. (2012). Helicopter parents and landing pad kids: Intense parental support of grown children. Journal of Marriage and Family, 74(4), 880-896. https://doi.org/10.1111/j.1741-3737.2012.00987.x

Fraley, R. C., Heffernan, M. E., Vicary, A. M., \& Brumbaugh, C. C. (2011). The experiences in close relationships_-Relationship Structures Questionnaire: A method for assessing attachment orientations across relationships. Psychological Assessment, 23(3), 615625. https://doi.org/10.1037/a0022898

Fryt, J., \& Szczygieł, M. (2021). Positive and Negative Risk Taking: Age Patterns and Predictors. https://doi.org/10.13140/RG.2.2.29164.69766 
Gamble, S. A., \& Roberts, J. E. (2005). Adolescents' perceptions of primary caregivers and cognitive style: The roles of attachment security and gender. Cognitive Therapy and Research, 29(2), 123-141. https://doi.org/10.1007/s10608-005-3160-7

Gardner, A. A., Zimmer-Gembeck, M. J., \& Campbell, S. M. (2019). Attachment and emotion regulation: A person-centred examination and relations with coping with rejection, friendship closeness, and emotional adjustment. British Journal of Developmental Psychology, 38(1), 125-143. https://doi.org/10.1111/bjdp.12310

Gecas, V., \& Schwalbe, M. L. (1986). Parental behavior and adolescent self-esteem. Journal of Marriage and the Family, 48(1), 37-46. https://doi.org/10.2307/352226

Gentner, D. (1988). Metaphor as structure mapping: The relational shift. Child Development, 59(1), 47-59. https://doi.org/10.2307/1130388

Goodman, E., Adler, N. E., Kawachi, I., Frazier, A. L., Huang, B., \& Colditz, G. A. (2001). Adolescents' Perceptions of Social Status: Development and Evaluation of a New Indicator. Pediatrics, 108(2). doi:10.1542/peds.108.2.e31

Gresham, D., \& Gullone, E. (2012). Emotion regulation strategy use in children and adolescents: The explanatory roles of personality and attachment. Personality and Individual Differences, 52(5), 616-621. https://doi.org/10.1016/j.paid.2011.12.016

Griffin, K. W., Botvin, G. J., Scheier, L. M., Diaz, T., \& Miller, N. L. (2000). Parenting practices as predictors of substance use, delinquency, and aggression among urban minority youth: Moderating effects of family structure and gender. Psychology of Addictive Behaviors, 14(2), 174-184. https://doi.org/10.1037/0893-164x.14.2.174 
Grolnick, W. S., \& Ryan, R. M. (1989). Parent styles associated with children's self-regulation and competence in school. Journal of Educational Psychology, 81(2), 143-154. https://doi.org/10.1037/0022-0663.81.2.143

Gross, J. J. (1998). The emerging Field of emotion regulation: An integrative review. Review of General Psychology, 2(3), 271-299. https://doi.org/10.1037/1089-2680.2.3.271

Gross, J. J., \& John, O. P. (2003). Individual differences in two emotion regulation processes: Implications for affect, relationships, and well-being. Journal of Personality and Social Psychology, 85(2), 348-362. https://doi.org/10.1037/0022-3514.85.2.348

Gross, J. J., \& Thompson, R. A. (2007). Emotion Regulation: Conceptual Foundations. In J. J. Gross (Ed.), Handbook of Emotion Regulation (pp. 3-24). The Guilford Press.

Gross, J. T., \& Cassidy, J. (2019). Expressive suppression of negative emotions in children and adolescents: Theory, data, and a guide for future research. Developmental Psychology, 55(9), 1938-1950. https://doi.org/10.1037/dev0000722

Gullone, E., \& Taffe, J. (2012). The emotion regulation questionnaire for children and adolescents (ERQ-CA): A psychometric evaluation. Psychological Assessment, 24(2), 409-417. https://doi.org/10.1037/a0025777

Hannah, S. T., Sweeney, P. J., \& Lester, P. B. (2007). Toward a courageous mindset: The subjective act and experience of courage. The Journal of Positive Psychology, 2(2), 129135. doi:10.1080/17439760701228854

Harris, H. (1999). Courage as a management virtue. Business and Professional Ethics Journal, 18(3), 27-46. https://doi.org/10.5840/bpej1999183/416

Hasking, P. A., Coric, S. J., Swannell, S., Martin, G., Thompson, H. K., \& Frost, A. D. (2010). Brief report: Emotion regulation and coping as moderators in the relationship between 
personality and self-injury. Journal of Adolescence, 33(5), 767-773. https://doi.org/10.1016/j.adolescence.2009.12.006

Hayes, A. F. (2013). Introduction to mediation, moderation, and conditional process analysis: A regression-based approach. Journal of Educational Measurement, 51, 335-337. doi:10.1111/jedm.12050

Howard, M. C., \& Alipour, K. K. (2014). Does the courage measure really measure courage? A theoretical and empirical evaluation. The Journal of Positive Psychology, 9(5), 449-459. https://doi.org/10.1080/17439760.2014.910828

Howard, M. C., Farr, J. L., Grandey, A. A., \& Gutworth, M. B. (2016). The creation of the workplace social courage scale (WSCS): An investigation of internal consistency, psychometric properties, validity, and utility. Journal of Business and Psychology, 32(6), 673-690. https://doi.org/10.1007/s10869-016-9463-8

Howard, M. S., \& Medway, F. J. (2004). Adolescents' attachment and coping with stress. Psychology in the Schools, 41(3), 391-402. https://doi.org/10.1002/pits.10167

Hung, M., Bounsanga, J., \& Voss, M. W. (2017). Interpretation of correlations in clinical research. Postgraduate Medicine, 129(8), 902-906. https://doi.org/10.1080/00325481.2017.1383820

Ickes, W. J., \& Layden, M. A. (1978). Attributional styles. In J. H. Harvey, W. J. Ickes, \& R. F. Kidd (Eds.), New directions in attribution research Vol. 2, (pp. 119-152). Hillsdale, NJ: Lawrence Erlbaum.

Joussemet, M., Landry, R., \& Koestner, R. (2008). A self-determination theory perspective on parenting. Canadian Psychology/Psychologie canadienne, 49(3), 194-200. https://doi.org/10.1037/a0012754 
Kim, J. H., Reid, C. A., McMahon, B., Gonzalez, R., Lee, D. H., \& Keck, P. (2016). Measuring the virtues and character traits of rehabilitation clients: The adapted inventory of virtues and strengths. Journal of Occupational Rehabilitation, 26(1), 32-44. https://doi.org/10.1007/s10926-015-9619-9

Kinsella, E., Ritchie, T., \& Igou, E. (2017). On the bravery and courage of heroes: Considering gender. Heroism Science: An Interdisciplinary Journal, 2(1), 1-14. https://doi.org/10.26736/hs.2017.01.04

Klimes-Dougan, B., Brand, A. E., Zahn-Waxler, C., Usher, B., Hastings, P. D., Kendziora, K., \& Garside, R. B. (2007). Parental Emotion Socialization in Adolescence: Differences in Sex, Age and Problem Status. Social Development, 16(2), 326-342. https://doi.org/10.1111/j.1467-9507.2007.00387.x

Koehn, A. J., \& Kerns, K. A. (2018). Parent-child attachment: Meta-analysis of associations with parenting behaviors in middle childhood and adolescence. Attachment \& Human Development, 20(4), 378-405. https://doi.org/10.1080/14616734.2017.1408131

Koerner, M. M. (2014). Courage as identity work: Accounts of workplace courage. Academy of Management Journal, 57(1), 63-93. https://doi.org/10.5465/amj.2010.0641

Kouros, C. D., Pruitt, M. M., Ekas, N. V., Kiriaki, R., \& Sunderland, M. (2017). Helicopter Parenting, Autonomy Support, and College Students' Mental Health and Well-being: The Moderating Role of Sex and Ethnicity. Journal of Child and Family Studies, 26(3), 939949. https://doi.org/10.1007/s10826-016-0614-3

Kristjánsson, Á. L., \& Sigfúsdóttir, I. D. (2009). The Role of Parental Support, Parental Monitoring, and Time Spent With Parents in Adolescent Academic Achievement in 
Iceland: A Structural Model of Gender Differences. Scandinavian Journal of Educational Research, 53(5), 481-496. https://doi.org/10.1080/00313830903180786

Krumpal, I. (2013). Determinants of social desirability bias in sensitive surveys: A literature review. Quality \& Quantity, 47(4), 2025-2047. https://doi.org/10.1007/s11135-011-9640$\underline{9}$

Lampert, J. N. (2009). Parental attachment styles and traditional undergraduates' adjustment to college: testing the "helicopter parent" phenomenon (Doctoral dissertation). http://commons.pacificu.edu/spp/57

Lantrip, C., Isquith, P. K., Koven, N. S., Welsh, K., \& Roth, R. M. (2015). Executive function and emotion regulation strategy use in adolescents. Applied Neuropsychology: Child, 5(1), 50-55. https://doi.org/10.1080/21622965.2014.960567

Larsen, K. S., \& Giles, H. (1976). Survival or courage as human motivation: Development of an attitude scale. Psychological Reports, 39(1), 299-302. https://doi.org/10.2466/pr0.1976.39.1.299

Latkin, C. A., Mai, N. V. T., Ha, T. V., Sripaipan, T., Zelaya, C., Le Minh, N., Morales, G., \& Go, V. F. (2016). Socially desirability response bias and other factors that may influence selfreports of substance use and HIV risk behaviors: A qualitative study of drug users in Vietnam. AIDS Education and Prevention : Official Publication of the International Society for AIDS Education, 28(5), 417-425. https://doi.org/10.1521/aeap.2016.28.5.417

Lee, A., \& Hankin, B. L. (2009). Insecure attachment, dysfunctional attitudes, and low selfesteem predicting prospective symptoms of depression and anxiety during adolescence. Journal of Clinical Child \& Adolescent Psychology, 38(2), 219-231. https://doi.org/10.1080/15374410802698396 
Lennarz, H. K., Lichtwarck-Aschoff, A., Timmerman, M. E., \& Granic, I. (2017). Emotion differentiation and its relation with emotional well-being in adolescents. Cognition and Emotion, 32(3), 651-657. https://doi.org/10.1080/02699931.2017.1338177

Lopez, S. J., O'Byrne, K. K., \& Petersen, S. (2003). Profiling courage. Positive psychological assessment: A handbook of models and measures, 185-197. https://doi.org/10.1037/10612-012

Maddi, S. R. (2004). Hardiness: An Operationalization of existential courage. Journal of Humanistic Psychology, 44(3), 279-298. https://doi.org/10.1177/0022167804266101

Magnano, P., Paolillo, A., Platania, S., \& Santisi, G. (2017). Courage as a potential mediator between personality and coping. Personality and Individual Differences, 111, 13-18. https://doi.org/10.1016/j.paid.2017.01.047

Markiewicz, D., Lawford, H., Doyle, A. B., \& Haggart, N. (2006). Developmental Differences in Adolescents' and Young Adults' Use of Mothers, Fathers, Best Friends, and Romantic Partners to Fulfill Attachment Needs. Journal of Youth and Adolescence, 35(1), 121-134. https://doi.org/10.1007/s10964-005-9014-5

Markus, H. R., \& Kitayama, S. (1991). Cultural Variation in the Self-Concept. In J. Strauss \& G. R. Goethals (Eds.), The Self: Interdisciplinary Approaches (pp. 18-48). Springer. https://doi.org/10.1007/978-1-4684-8264-5_2

Mauss, I. B., \& Butler, E. A. (2010). Cultural context moderates the relationship between emotion control values and cardiovascular challenge versus threat responses. Biological Psychology, 84(3), 521-530. https://doi.org/10.1016/j.biopsycho.2009.09.010

Mikulincer, M., \& Arad, D. (1999). Attachment working models and cognitive openness in close relationships: A test of chronic and temporary accessibility effects. Journal of Personality and Social Psychology, 77(4), 710-725. https://doi.org/10.1037/0022-3514.77.4.710 
Mikulincer, M., Dolev, T., \& Shaver, P. R. (2004). Attachment-related strategies during thought suppression: Ironic rebounds and vulnerable self-representations. Journal of Personality and Social Psychology, 87(6), 940-956. https://doi.org/10.1037/0022-3514.87.6.940

Mikulincer, M., Gillath, O., Halevy, V., Avihou, N., Avidan, S., \& Eshkoli, N. (2001). Attachment theory and reactions to others' needs: Evidence that activation of the sense of attachment security promotes empathic responses. Journal of Personality and Social Psychology, 81(6), 1205-1224.https://doi.org/10.1037/0022-3514.81.6.1205

Mikulincer, M., Shaver, P.R. \& Pereg, D. (2003). Attachment Theory and Affect Regulation: The Dynamics, Development, and Cognitive Consequences of Attachment-Related Strategies. Motivation and Emotion, 27, 77-102. https://doi.org/10.1023/A:1024515519160

Mikulincer, M., Shaver, P. R., Sapir-Lavid, Y., \& Avihou-Kanza, N. (2009). What's inside the minds of securely and insecurely attached people? The secure-base script and its associations with attachment-style dimensions. Journal of Personality and Social Psychology, 97(4), 615-633. https://doi.org/10.1037/a0015649

Morrongiello, B. A., \& Hogg, K. (2004). Mothers' reactions to children misbehaving in ways that can lead to injury: Implications for gender differences in children's risk taking and injuries. Sex Roles, 50, 103-118.

http://dx.doi.org/10.1023/B:SERS.0000011076.43831.a6

Muris, P., Mayer, B., \& Schubert, T. (2009). "You might belong in Gryffindor”: Children's courage and its relationships to anxiety symptoms, Big Five personality traits, and sex roles. Child Psychiatry \& Human Development, 41(2), 204-213. https://doi.org/10.1007/s10578-009-0161-x 
Muris, P., \& Meesters, C. (2002). Symptoms of anxiety disorders and teacher-reported school functioning of normal children. Psychological Reports, 91(2), 588-590. https://doi.org/10.2466/pr0.2002.91.2.588

Nelson, J. K. (2009). Mario Mikulincer, Phillip R. Shaver: Attachment in adulthood: Structure, dynamics and change. Clinical Social Work Journal, 37(2), 179-180. https://doi.org/10.1007/s10615-009-0193-5

Noftle, E. E., \& Shaver, P. R. (2006). Attachment dimensions and the Big Five personality traits: Associations and comparative ability to predict relationship quality. Journal of Research in Personality, 40(2), 179-208. https://doi.org/10.1016/j.jrp.2004.11.003

Norton, P. J., \& Weiss, B. J. (2009). The role of courage on behavioral approach in a feareliciting situation: A proof-of-concept pilot study. Journal of Anxiety Disorders, 23(2), 212-217. https://doi.org/10.1016/j.janxdis.2008.07.002

Nurmi, J., \& Pulliainen, H. (1991). The changing parent-child relationship, self-esteem, and intelligence as determinants of orientation to the future during early adolescence. Journal of Adolescence, 14(1), 35-51. https://doi.org/10.1016/0140-1971(91)90044-r

O’Byrne, K. K., Lopez, S. J., \& Peterson, S. (2000). Building a theory of courage: A precursor to change? Paper presented at the 108th Annual Convention of the American Psychological Association, Washington, DC.

Opitz, P. C., Rauch, L. C., Terry, D. P., \& Urry, H. L. (2012). Prefrontal mediation of age differences in cognitive reappraisal. Neurobiology of Aging, 33(4), 645-655. https://doi.org/10.1016/j.neurobiolaging.2010.06.004

Padilla-Walker, L. M., \& Nelson, L. J. (2012). Black hawk down?: Establishing helicopter parenting as a distinct construct from other forms of parental control during emerging 
adulthood. Journal of Adolescence, 35(5), 1177-1190.

https://doi.org/10.1016/j.adolescence.2012.03.007

Peterson, G. W., \& Bush, K. R. (1999). Predicting adolescent autonomy from parents:

Relationship connectedness and restrictiveness. Sociological Inquiry, 69(3), 431-

457. https://doi.org/10.1111/j.1475-682x.1999.tb00880.x

Peterson, C., \& Seligman, M. E. P. (2004). Character strengths and virtues: A handbook and classification. American Psychological Association; Oxford University Press.

Putman, D. (1997). Psychological courage. Philosophy, Psychiatry, \& Psychology, 4(1), 1-11. https://doi.org/10.1353/ppp.1997.0008

Rate, C. R., Clarke, J. A., Lindsay, D. R., \& Sternberg, R. J. (2007). Implicit theories of courage. The Journal of Positive Psychology, 2(2), 80-

98.https://doi.org/10.1080/17439760701228755

Read, D. L., Clark, G. I., Rock, A. J., \& Coventry, W. L. (2018). Adult attachment and social anxiety: The mediating role of emotion regulation strategies. PLOS ONE, 13(12), e0207514.https://doi.org/10.1371/journal.pone.0207514

Reed, K., Duncan, J. M., Lucier-Greer, M., Fixelle, C., \& Ferraro, A. J. (2016). Helicopter parenting and emerging adult self-efficacy: Implications for mental and physical health. Journal of Child and Family Studies, 25(10), 3136-3149. https://doi.org/10.1007/s10826$\underline{016-0466-\mathrm{X}}$

Riediger, M., \& Klipker, K. (2014). Emotion regulation in adolescence. In J. J. Gross (Ed.), Handbook of Emotion Regulation (pp. 187-202). The Guilford Press. 
Robbins, R. J. (1994). An assessment of perceptions of parental autonomy support and control: Child and parent correlates. Unpublished Doctoral Dissertation, Department of Psychology, University of Rochester.

Rosenberg, M. (1965). Society and the adolescent self-image. Princeton, NJ: Princeton University Press.

Rosenberg, M. (1989). Society and the Adolescent Self-Image. Revised Edition. Middletown, CT: Wesleyan University Press.

Ryan, R. M., Stiller, J. D., \& Lynch, J. H. (1994). Representations of relationships to teachers, parents, and friends as predictors of academic motivation and self-esteem. The Journal of Early Adolescence, 14(2), 226-249. https://doi.org/10.1177/027243169401400207

Sanders, R. A. (2013). Adolescent Psychosocial, Social, and Cognitive Development. Pediatrics in Review, 34(8), 354-359. https://doi.org/10.1542/pir.34-8-354

Sarros, J. C., \& Cooper, B. K. (2006). Building character: A leadership essential. Journal of Business and Psychology, 21(1), 1-22. https://doi.org/10.1007/s10869-005-9020-3

Schäfer, J. Ö, Naumann, E., Holmes, E. A., Tuschen-Caffier, B., \& Samson, A. C. (2016). Emotion Regulation Strategies in Depressive and Anxiety Symptoms in Youth: A MetaAnalytic Review. Journal of Youth and Adolescence, 46(2), 261-276. doi:10.1007/s10964-016-0585-0

Shaffer, J. P. (1995). Multiple Hypothesis Testing. Annual Review of Psychology, 46(1), 561584. https://doi.org/10.1146/annurev.ps.46.020195.003021

Schiffrin, H. H., Erchull, M. J., Sendrick, E., Yost, J. C., Power, V., \& Saldanha, E. R. (2019). The Effects of Maternal and Paternal Helicopter Parenting on the Self-determination and 
Well-being of Emerging Adults. Journal of Child and Family Studies, 28(12), 3346-3359. doi:10.1007/s10826-019-01513-6

Schiffrin, H. H., Liss, M., Miles-McLean, H., Geary, K. A., Erchull, M. J., \& Tashner, T. (2013). Helping or hovering? The effects of helicopter parenting on college students' well-being. Journal of Child and Family Studies, 23(3), 548-557. https://doi.org/10.1007/s10826$\underline{013-9716-3}$

Schweizer, S., Gotlib, I. H., \& Blakemore, S. (2020). The role of affective control in emotion regulation during adolescence. Emotion, 20(1), 80-86. https://doi.org/10.1037/emo0000695

Schäfer, J. Ö., Naumann, E., Holmes, E. A., Tuschen-Caffier, B., \& Samson, A. C. (2016). Emotion regulation strategies in depressive and anxiety symptoms in youth: A metaanalytic review. Journal of Youth and Adolescence, 46(2), 261-276. https://doi.org/10.1007/s10964-016-0585-0

Segrin, C., Woszidlo, A., Givertz, M., Bauer, A., \& Taylor Murphy, M. (2012). The association between Overparenting, parent-child communication, and entitlement and adaptive traits in adult children. Family Relations, 61(2), 237-252. https://doi.org/10.1111/j.17413729.2011.00689.x

Singer, J. D., \& Willett, J. B. (2003). Applied longitudinal data analysis: Modeling change and event occurrence (pp. xx, 644). Oxford University Press. https://doi.org/10.1093/acprof:oso/9780195152968.001.0001

Sonnentag, T. L., \& Barnett, M. A. (2013). An exploration of moral rebelliousness with adolescents and young adults. Ethics \& Behavior, 23(3), 214-236. https://doi.org/10.1080/10508422.2012.739943 
Sonnentag, T. L., \& Barnett, M. A. (2016). Role of moral identity and moral courage characteristics in adolescents' tendencies to be a moral rebel. Ethics \& Behavior, 26(4), 277-299. https://doi.org/10.1080/10508422.2015.1012765

Soto, J. A., Perez, C. R., Kim, Y.-H., Lee, E. A., \& Minnick, M. R. (2011). Is expressive suppression always associated with poorer psychological functioning? A cross-cultural comparison between European Americans and Hong Kong Chinese. Emotion, 11(6), 1450-1455. https://doi.org/10.1037/a0023340

Spear, L. P. (2011). Rewards, aversions and affect in adolescence: Emerging convergences across laboratory animal and human data. Developmental Cognitive Neuroscience, 1(4), 390403. https://doi.org/10.1016/j.den.2011.08.001

Spielmann, S. S., Maxwell, J. A., MacDonald, G., \& Baratta, P. L. (2013). Don’t Get Your Hopes Up: Avoidantly Attached Individuals Perceive Lower Social Reward When There Is Potential for Intimacy. Personality and Social Psychology Bulletin, 39(2), 219-236. https://doi.org/10.1177/0146167212472541

Springer, T.R. (2012). Developing a Cohesive Identity through Courage and Adventure Therapy. Adler Graduate School, Minnesota.

Srivastva, S., \& Cooperrider, D. L. (1998). Organizational wisdom and executive courage (1st ed., Ser. The new lexington press management and organization sciences series). New Lexington Press.

Sroufe, L. A. (2005). Attachment and development: A prospective, longitudinal study from birth to adulthood. Attachment \& Human Development, 7(4), 349-367. https://doi.org/10.1080/14616730500365928 
Steinberg, L. (2008). A social neuroscience perspective on adolescent risk-taking. Developmental Review, 28(1), 78-106. https://doi.org/10.1016/j.dr.2007.08.002

Steinberg, L. (2004). Risk Taking in Adolescence: What Changes, and Why? Annals of the New York Academy of Sciences, 1021(1), 51-58. https://doi.org/10.1196/annals.1308.005

Steinberg, L. (2007). Risk Taking in Adolescence: New Perspectives from Brain and Behavioral Science. Current Directions in Psychological Science, 16(2), 55-59.

Sternberg, R. J. (1985). Implicit theories of intelligence, creativity, and wisdom. Journal of Personality and Social Psychology, 49(3), 607-627. https://doi.org/10.1037/0022$\underline{3514.49 .3 .607}$

Szagun, G. (1992). Age-related changes in children's understanding of courage. The Journal of Genetic Psychology, 153(4), 405-420. https://doi.org/10.1080/00221325.1992.10753736

Thompson, R. A. (2008). Early attachment and later development: Familiar questions, new answers. In J. Cassidy \& P. R. Shaver (Eds.), Handbook of attachment: Theory, research, and clinical applications (pp. 348-365). The Guilford Press.

Valenzuela Jr., A. (1999). Gender roles and settlement activities among children and their immigrant families. American Behavioral Scientist, 42(4), 720-742. https://doi.org/10.1177/00027649921954435

van Ingen, D.J., Freiheit, S.R., Steinfeldt, J.A., Moore, L.L., Wimer, D.J., Knutt, A.D., Scapinello, S. \& Roberts, A. (2015). Helicopter Parenting: The Effect of an Overbearing Caregiving Style on Peer Attachment and Self-Efficacy. Journal of College Counseling, 18, 7-20. doi:10.1002/j.2161-1882.2015.00065.x

Van Petegem, S., Brenning, K., Baudat, S., Beyers, W., \& Zimmer-Gembeck, M. J. (2018). Intimacy development in late adolescence: Longitudinal associations with perceived 
parental autonomy support and adolescents' self-worth. Journal of Adolescence, 65, 111122. https://doi.org/10.1016/j.adolescence.2018.03.008

Weissman, M. M., \& Merikangas, K. R. (1986). The epidemiology of anxiety and panic disorders: An update. Journal of Clinical Psychiatry, 47, 11-7.

Weston, S. J., \& Jackson, J. J. (2018). The role of vigilance in the relationship between neuroticism and health: A registered report. Journal of Research in Personality, 73, 2734. https://doi.org/10.1016/j.jrp.2017.10.005

Worline, M. C. (2010). Understanding the role of courage in social life. The psychology of courage: Modern research on an ancient virtue, 209-226. https://doi.org/10.1037/12168011 


\section{Table 1}

Summary of sex, age, and race/ethnicities of sample

\begin{tabular}{llcc}
\hline Variable & & $N=203$ & $\%$ \\
\hline Sex & Male & & \\
& Female & 98 & 48.40 \\
Age at Time 1 & & 105 & 51.70 \\
& 14 & & \\
& 15 & 88 & 43.30 \\
& 16 & 73 & 36.00 \\
& 17 & 40 & 19.70 \\
Race/ Ethnicity & 1 & 0.50 \\
& & & \\
& White & 187 & 88.30 \\
& Black & 9 & 2.33 \\
& Hispanic & 10 & 1.87 \\
& Asian & 6 & 2.34 \\
& Native American & 3 & 0.47 \\
& Multiracial & 1 & 4.67 \\
\hline
\end{tabular}


Table 2

Summary statistics of variables and transformed variables

\begin{tabular}{|c|c|c|c|c|c|}
\hline Variable & $N$ & Mean & SD & Possible Range & Actual Range \\
\hline SES-ladder & 197 & 6.27 & 1.39 & $1.00-10.00$ & $3.00-9.00$ \\
\hline Difficulty paying bills & 199 & 3.35 & 0.70 & $1.00-4.00$ & $1.00-4.00$ \\
\hline Self-esteem & 195 & 29.73 & 6.39 & $10.00-40.00$ & $14.00-40.00$ \\
\hline Cognitive Reappraisal & 202 & 4.14 & 1.12 & $1.00-7.00$ & $1.00-7.00$ \\
\hline Expressive Suppression & 202 & 3.78 & 1.25 & $1.00-7.00$ & $1.00-6.75$ \\
\hline Mother Autonomy Support & 194 & 3.20 & 0.55 & $1.00-4.00$ & $1.10-4.00$ \\
\hline Father Autonomy Support & 186 & 3.17 & 0.59 & $1.00-4.00$ & $1.00-4.00$ \\
\hline Mother Attachment Anxiety & 190 & 1.66 & 0.76 & $1.00-5.00$ & $1.00-5.00$ \\
\hline Father Attachment Anxiety & 187 & 1.85 & 1.04 & $1.00-5.00$ & $1.00-5.00$ \\
\hline Mother Attachment Avoidant & 195 & 2.52 & 1.14 & $1.00-5.00$ & $1.00-5.00$ \\
\hline Father Attachment Avoidant & 188 & 2.91 & 1.21 & $1.00-5.00$ & $1.00-5.00$ \\
\hline Mother Helicopter Parenting & 196 & 2.79 & 0.82 & $1.00-5.00$ & $1.00-5.00$ \\
\hline Father Helicopter Parenting & 189 & 2.34 & 0.93 & $1.00-5.00$ & $1.00-4.40$ \\
\hline Courage & 203 & 4.54 & 1.01 & $1.00-7.00$ & $2.08-7.00$ \\
\hline \multicolumn{6}{|l|}{ Transformed Variables } \\
\hline Mother Attachment Anxiety & 190 & 0.18 & 0.17 & - & $0.00-0.70$ \\
\hline Father Attachment Anxiety & 187 & 0.21 & 0.21 & - & $0.00-0.70$ \\
\hline Mother Autonomy Support & 194 & 1.67 & 0.20 & - & $1.16-2.00$ \\
\hline Father Autonomy Support & 186 & 1.67 & 0.21 & - & $1.16-2.00$ \\
\hline
\end{tabular}


Table 3

Correlations between Time 1 Intrapersonal and Interpersonal Predictors and Time 3 Courage

\begin{tabular}{|c|c|c|c|c|c|c|c|c|c|c|c|c|c|}
\hline & 1. & 2. & 3. & 4. & 5. & 6. & 7. & 8. & 9. & 10. & 11. & 12. & 13. \\
\hline 1. SES- ladder & --- & & & & & & & & & & & & \\
\hline 2. Difficulty paying bills & $.55^{* * *}$ & --- & & & & & & & & & & & \\
\hline 3. Self-esteem & $.35^{* * *}$ & $.19^{* * * *}$ & --- & & & & & & & & & & \\
\hline 4. Reappraisal & .02 & .08 & $.40^{* * * *}$ & --- & & & & & & & & & \\
\hline 5. Suppression & $-.47^{* * *}$ & -.13 & $-.30^{* * *}$ & .01 & --- & & & & & & & & \\
\hline 6. Mother Autonomy & .11 & -.05 & $.36^{* * *}$ & .07 & -.08 & --- & & & & & & & \\
\hline 7. Father Autonomy & $.15^{*}$ & .02 & $.41^{* * * *}$ & -.03 & -.14 & $.72^{* * *}$ & --- & & & & & & \\
\hline 8. Mother Anxiety & $-.10^{*}$ & .06 & $-.36^{* * *}$ & -.14 & $.16^{*}$ & $-.46^{* *}$ & $-.29^{* * *}$ & --- & & & & & \\
\hline 9. Mother Avoidant & -.01 & .02 & $-.29^{* * *}$ & $-.23^{* * * *}$ & $.36^{* * * *}$ & $-.31^{* * * *}$ & $-.18^{* * *}$ & $.61^{* * *}$ & --- & & & & \\
\hline 10. Father Anxiety & $-.18^{* * *}$ & -.07 & $-.44^{* * *}$ & -.11 & .13 & $-.32^{* * *}$ & $-.41^{* * *}$ & $.62^{* * *}$ & $.21 *$ & --- & & & \\
\hline 11. Father Avoidant & $-.19^{*}$ & $-.18^{*}$ & $-.42^{* * *}$ & -.12 & $.24^{* *}$ & $-.23^{* *}$ & $-.46^{* * *}$ & $.30^{* *}$ & $.35^{* * *}$ & $.62^{* * * *}$ & --- & & \\
\hline 12. Mother HP & -.09 & -.02 & .07 & $.21^{* *}$ & -.12 & $-.19^{* *}$ & $-.23^{* *}$ & -.08 & $-.31^{* * * *}$ & -.02 & -.06 & --- & \\
\hline 13. Father HP & .13 & $.17^{*}$ & $.17^{*}$ & .09 & $-.17^{*}$ & $-.15^{*}$ & -.03 & .05 & -.10 & -.14 & $-.44^{* * * *}$ & $.44^{* * * *}$ & --- \\
\hline 14. Courage & $.20^{* *}$ & .07 & $.39^{* * * *}$ & $.23^{* *}$ & .04 & $.30^{* * * *}$ & $.23^{* *}$ & -.09 & -.08 & -.11 & -.14 & $-.16^{* *}$ & .03 \\
\hline
\end{tabular}

Note. Parental attachment anxiety is abbreviated each as Mother Anxiety and Father Anxiety. Parental attachment avoidant is abbreviated as Mother Avoidant and Father Avoidant. Helicopter parenting of parents is abbreviated as Mother HP and Father HP. 
Table 4

Hierarchical Regression Analysis for Interpersonal predictors of Time 3 Courage

\begin{tabular}{|c|c|c|c|c|c|}
\hline Variable & $\begin{array}{l}\text { Step1 } \\
\text { Beta }\end{array}$ & $\begin{array}{l}\text { Step } 2 \\
\text { Beta } \\
\end{array}$ & Variable & $\begin{array}{l}\text { Step1 } \\
\text { Beta }\end{array}$ & $\begin{array}{l}\text { Step } 2 \\
\text { Beta } \\
\end{array}$ \\
\hline Model 1 & & & Model 4 & & \\
\hline Gender & .13 & .13 & Gender & .14 & .13 \\
\hline SES-Ladder & $.17^{*}$ & $.17^{*}$ & SES-Ladder & $.18^{*}$ & $.17^{*}$ \\
\hline Attachment Avoidant Mother & - & -.06 & Attachment Avoidant Father & - & -.09 \\
\hline Attachment Anxiety Mother & - & -.02 & Attachment Anxiety Father & - & .00 \\
\hline$R^{2}$ & $.05^{* *}$ & .06 & $R^{2}$ & $.06^{* *}$ & .07 \\
\hline$\Delta R^{2}$ & .05 & .01 & $\Delta R^{2}$ & .06 & .01 \\
\hline Model 2 & & & Model 5 & & \\
\hline Gender & $.17^{*}$ & .13 & Gender & $.17^{*}$ & .12 \\
\hline SES-Ladder & $.16^{*}$ & .14 & SES-Ladder & $.19^{* *}$ & $.17^{*}$ \\
\hline Autonomy Support Mother & - & $.25^{* * *}$ & Autonomy Support Father & - & $.16^{*}$ \\
\hline$R^{2}$ & $.06^{* *}$ & $.12^{* * * *}$ & $R^{2}$ & $.07^{* *}$ & $.10^{*}$ \\
\hline$\Delta R^{2}$ & .06 & $.06^{* * *}$ & $\Delta R^{2}$ & .07 & $.02^{*}$ \\
\hline Model 3 & & & Model 6 & & \\
\hline Gender & $.16^{*}$ & $.16^{*}$ & Gender & $.17^{*}$ & $.17^{*}$ \\
\hline SES-ladder & $.16^{*}$ & $.15^{*}$ & SES-ladder & $.17^{*}$ & $.17^{*}$ \\
\hline Helicopter Parenting Mother & - & $-.15^{*}$ & Helicopter parenting Father & - & .02 \\
\hline$R^{2}$ & .06 & $.08^{*}$ & $R^{2}$ & $.06^{* *}$ & .06 \\
\hline$\Delta R^{2}$ & .06 & $.02^{*}$ & $\Delta R^{2}$ & .06 & .00 \\
\hline
\end{tabular}
coefficients. 


\section{Table 5}

Hierarchical Regression Analysis for Intrapersonal predictors of Time 3 Courage Variable

Model 7

Gender

SES-Ladder

Self-esteem

$R^{2}$

Step1 Step 2

$\Delta R^{2}$

Model 8

Gender

SES-Ladder

Cognitive Reappraisal

Expressive Suppression

$R^{2}$

\begin{tabular}{cc}
$.17^{*}$ & .09 \\
$.17^{*}$ & .06 \\
- & $.35^{* * *}$ \\
\hline $.07^{* *}$ & $.17^{* * *}$ \\
.07 & .10
\end{tabular}

$\Delta R^{2}$

$.15 \quad .14$

$.18 \quad .20$

$-.21^{* *}$

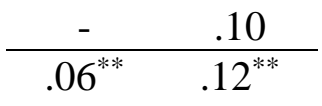

Note. *

$\Delta R^{2} \quad .06$

$.06 \quad .05$ coefficients. 


\section{Figure 1}

Mediating effect of self-esteem on the relationship between autonomy support of mother and courage. $N=190$.

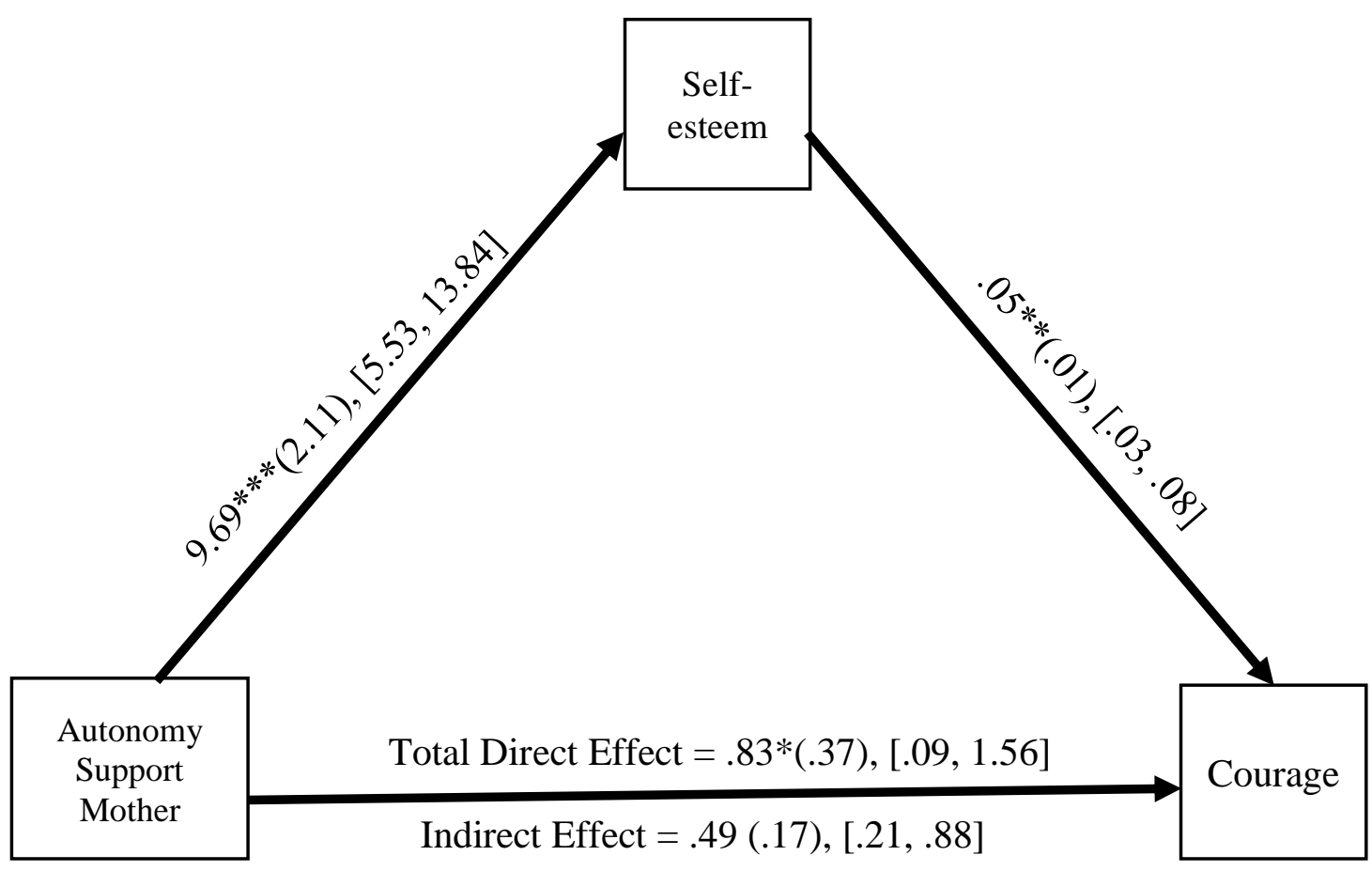

Figure 2

Mediating effect of self-esteem on the relationship between autonomy support of father and courage. $N=182$.

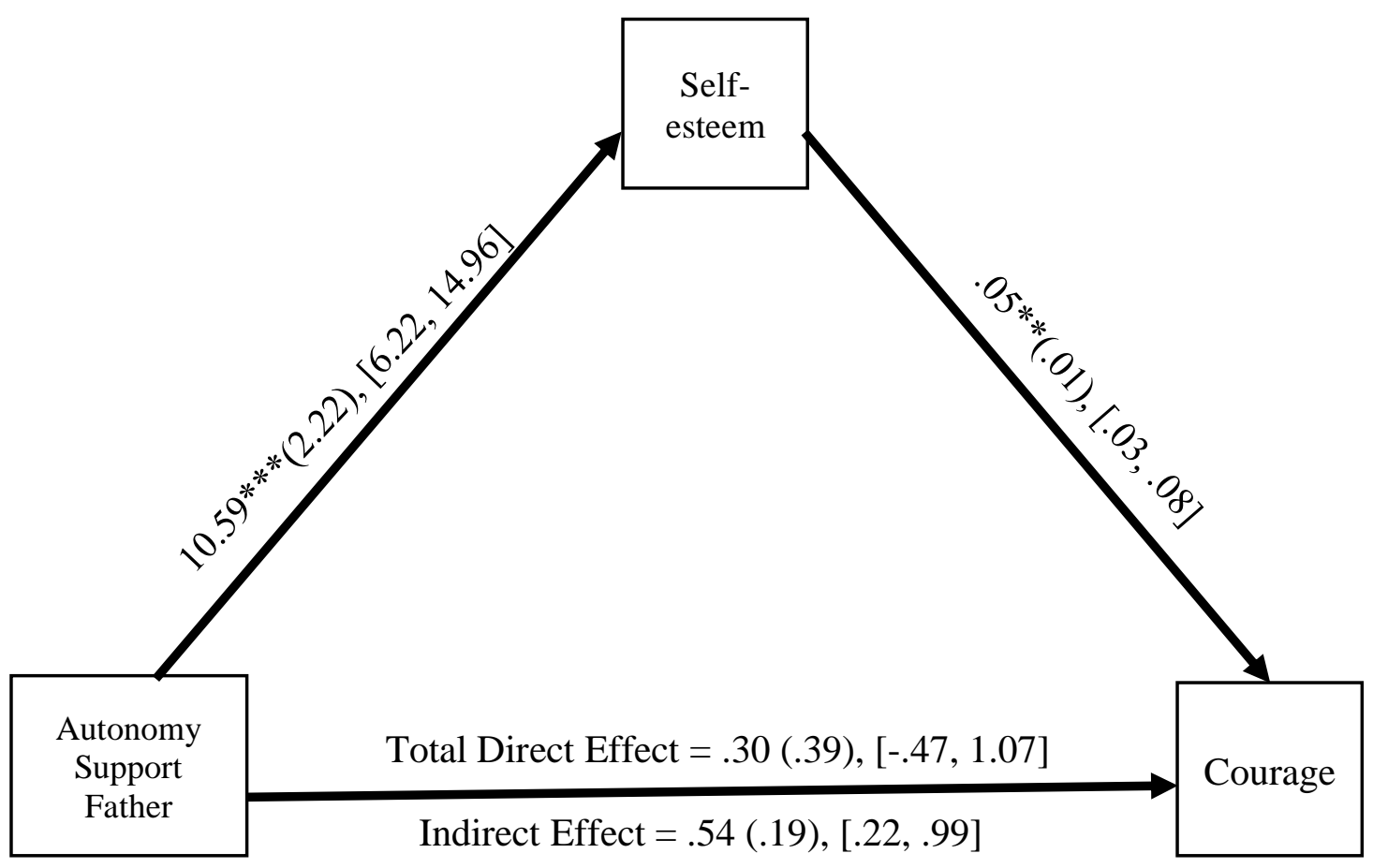




\section{Figure 3}

Mediating effect of self-esteem on the relationship between attachment-anxious to mother and courage. $N=186$.

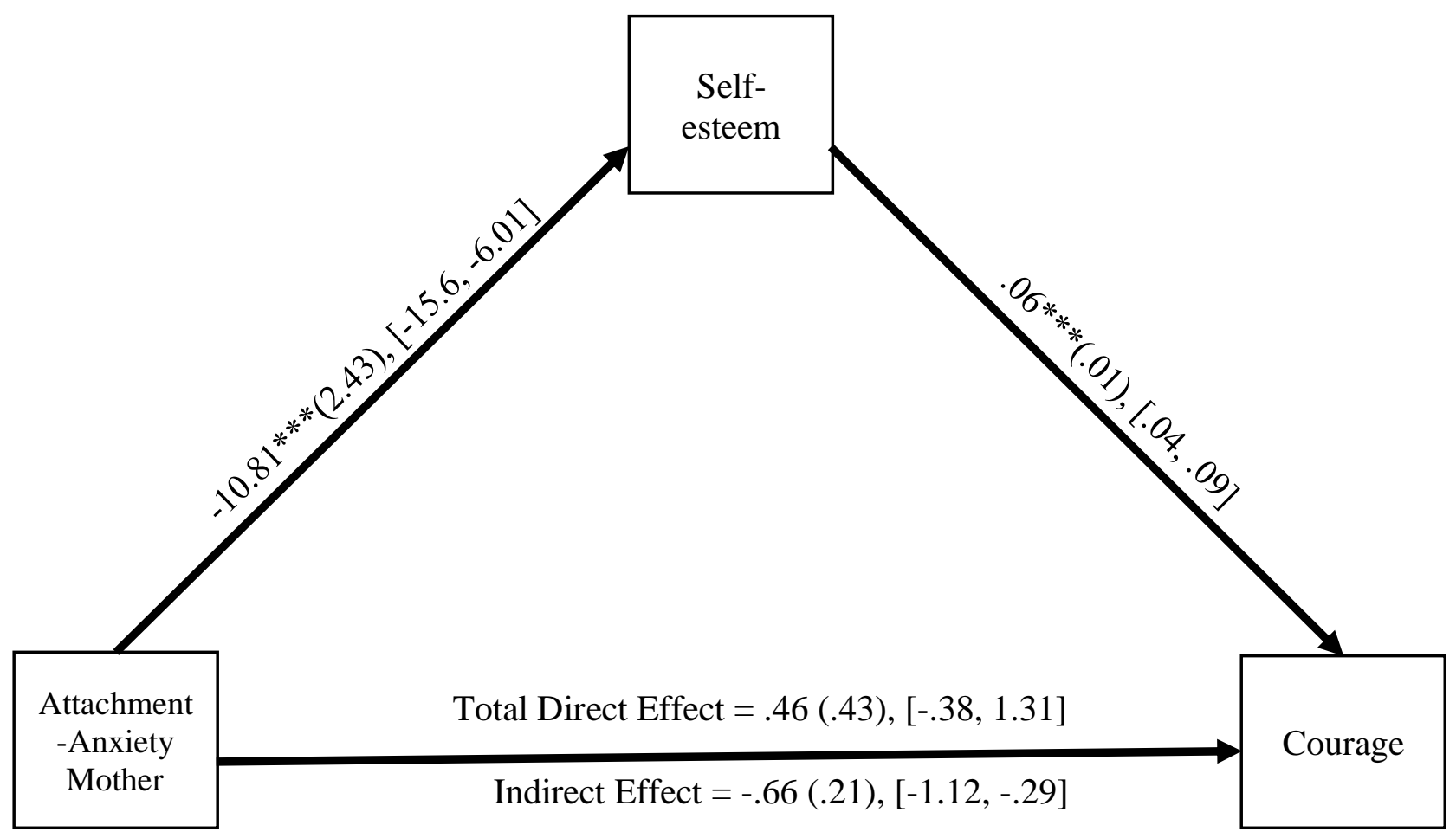

\section{Figure 4}

Mediating effect of self-esteem on the relationship between attachment-anxious to father and courage. $N=183$.

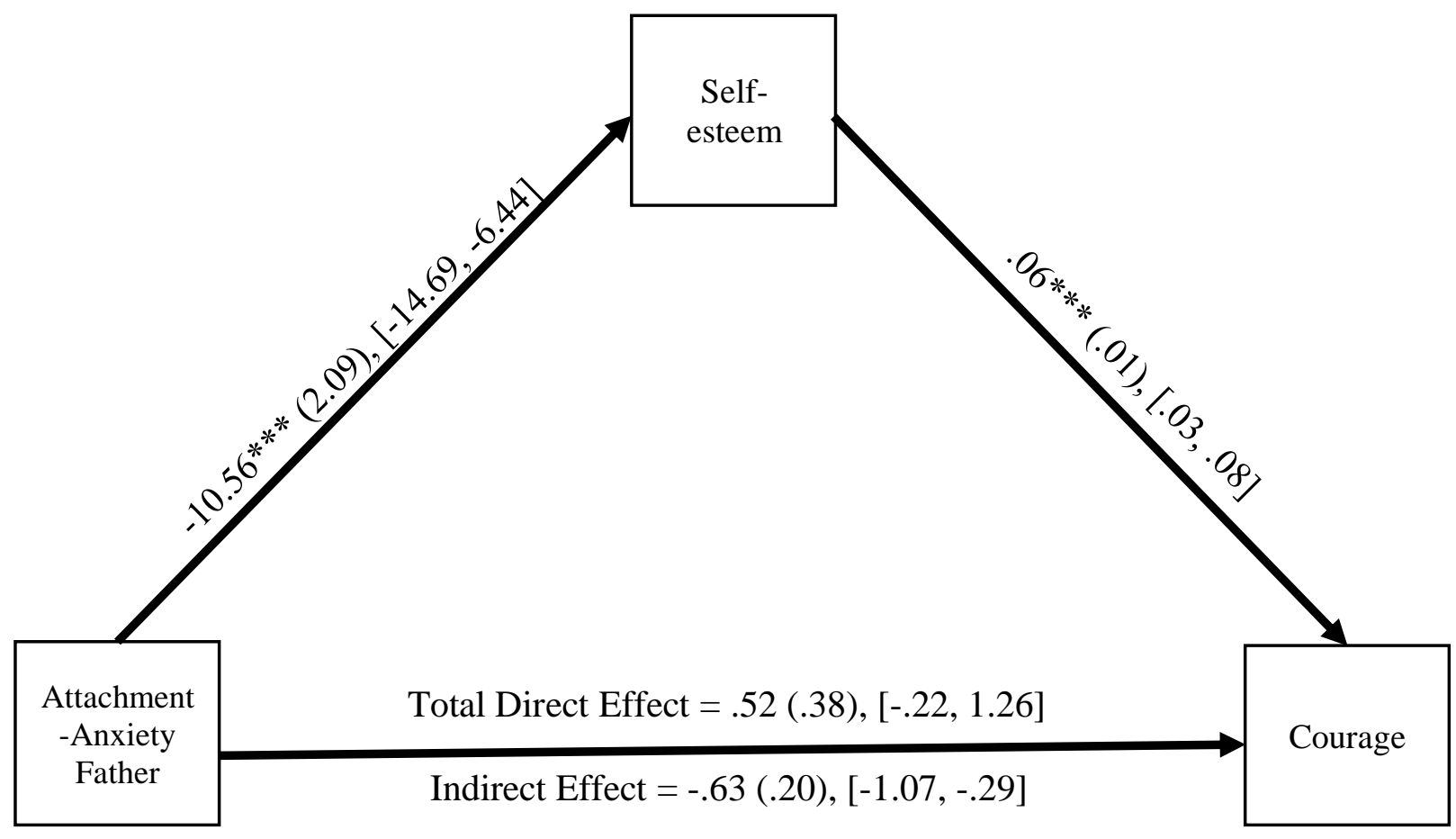




\section{Figure 5}

Mediating effect of self-esteem on the relationship between attachment-avoidant to mother and courage. $N=191$.

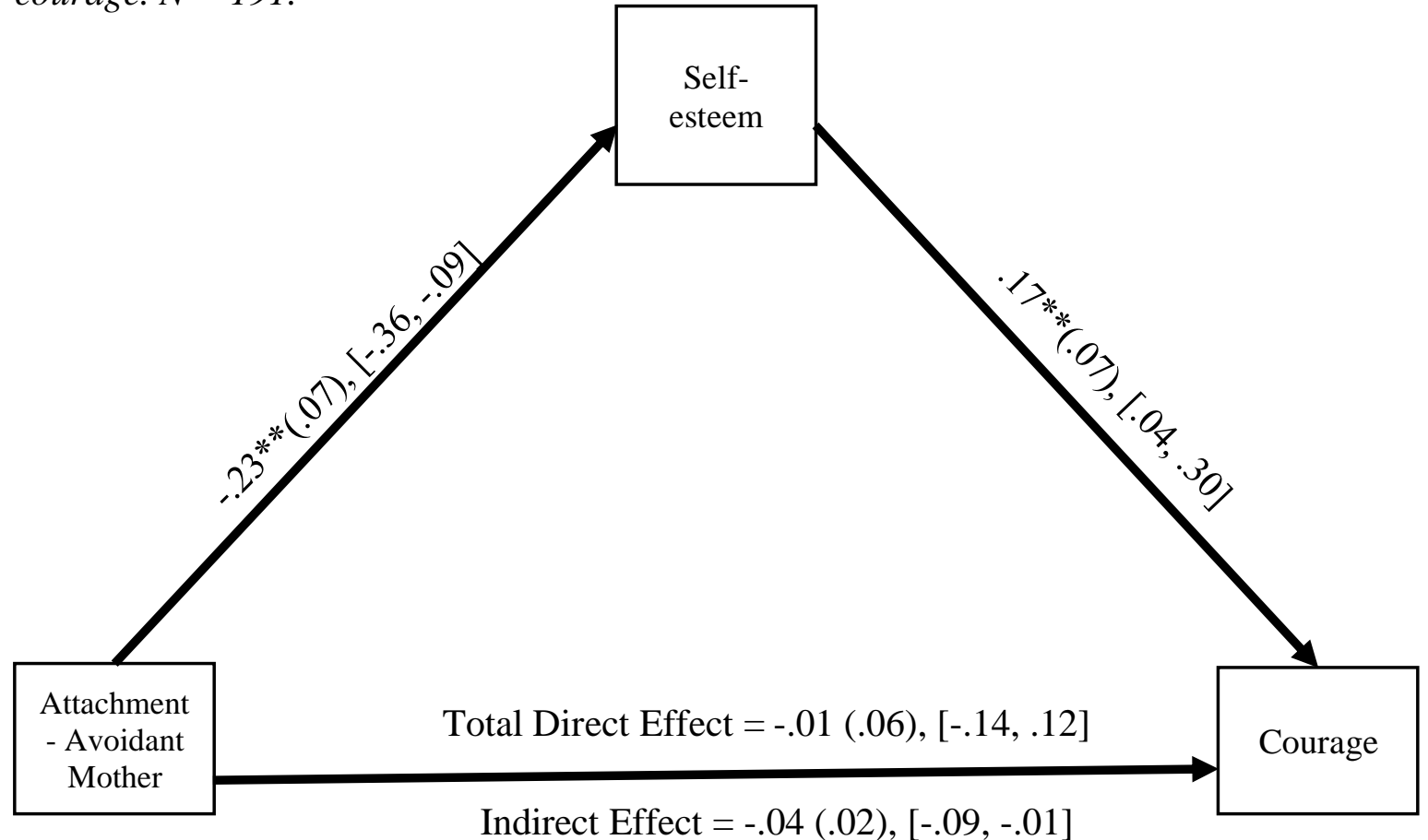

\section{Figure 6}

Mediating effect of self-esteem on the relationship between attachment- avoidant to father and courage. $N=184$.

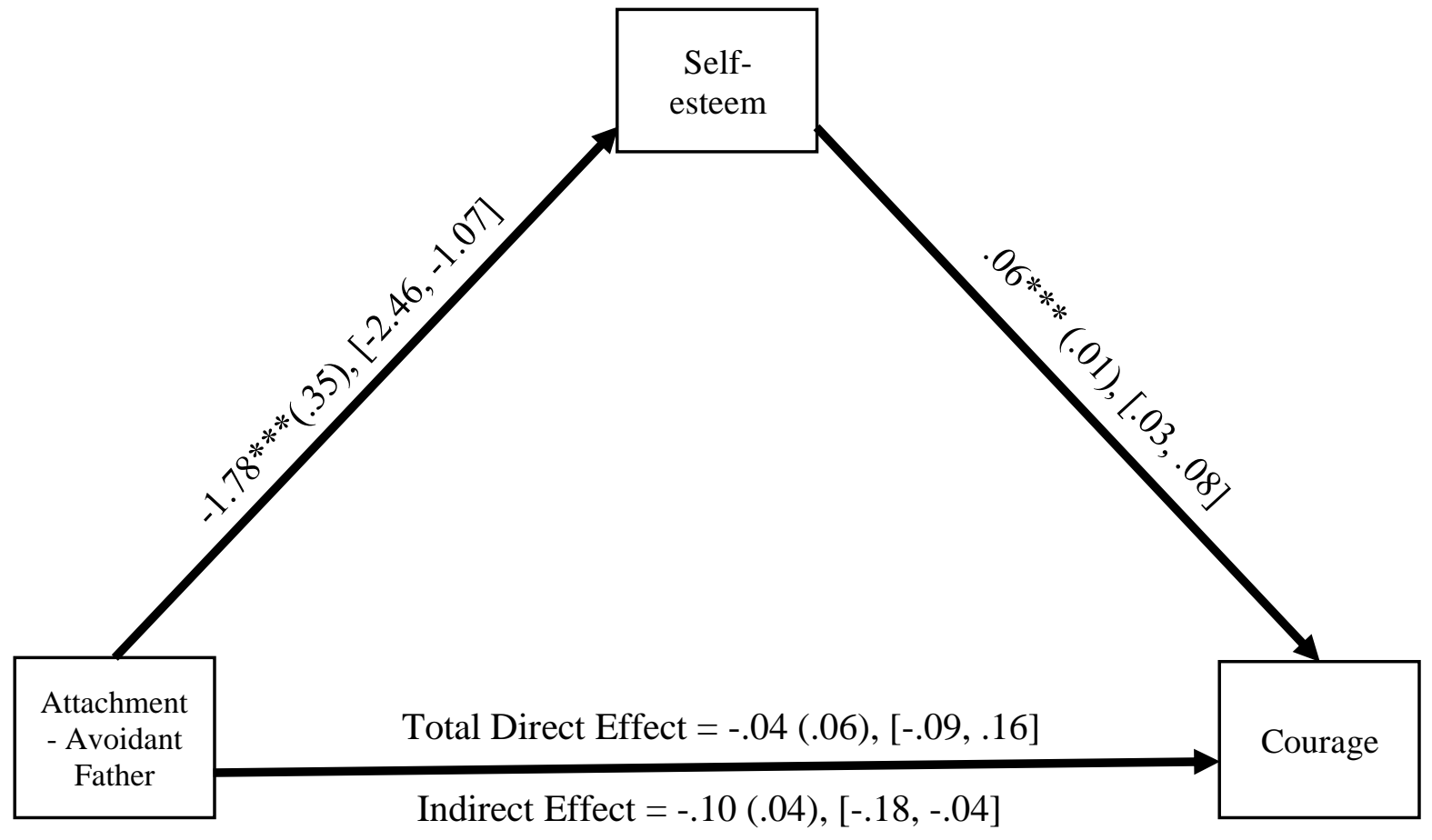




\section{Figure 7}

Mediating effect of cognitive reappraisal on the relationship between avoidant attachment to mother and courage. $N=194$.

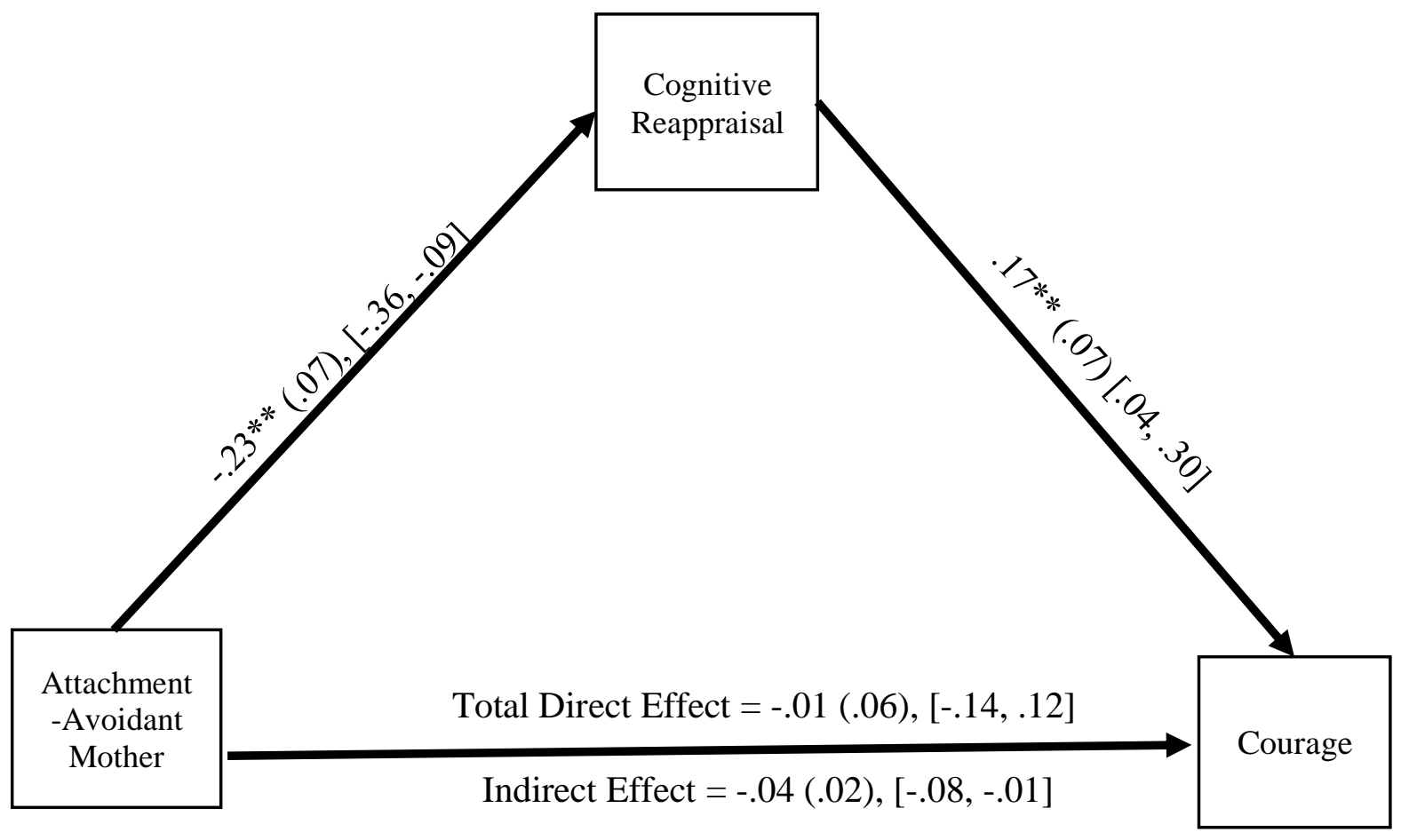

\section{Figure 8}

Mediating effect of cognitive reappraisal on the relationship between helicopter parenting of mothers and courage. $N=195$

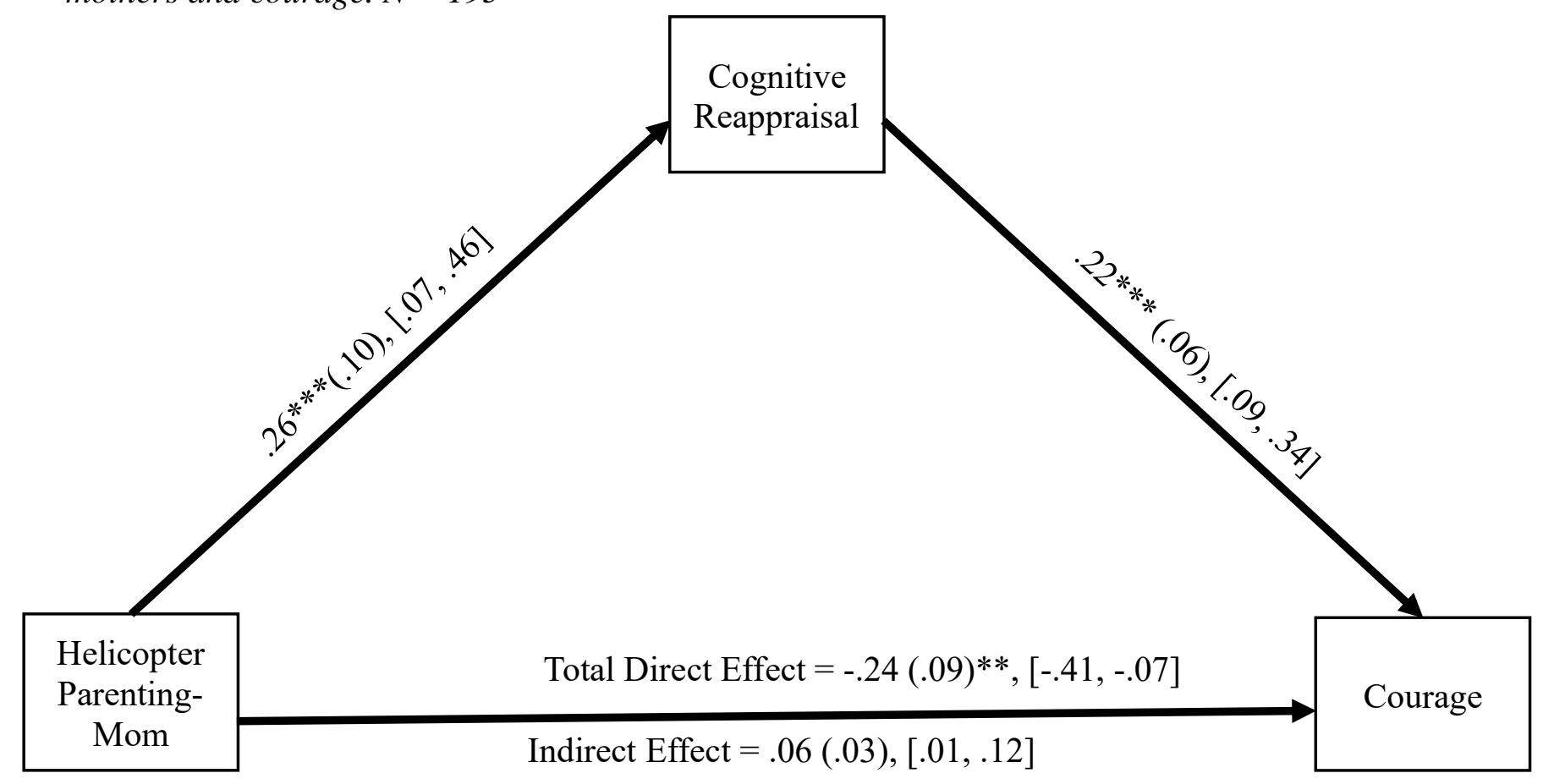




\section{Appendix A}

\section{Courage Measure}

84. Courage is defined as persistence or perseverancedespite having fear. It takes courage to engage and persist in scary or dangerous activities. Please carefully read each statement and rate how often you these apply to you.

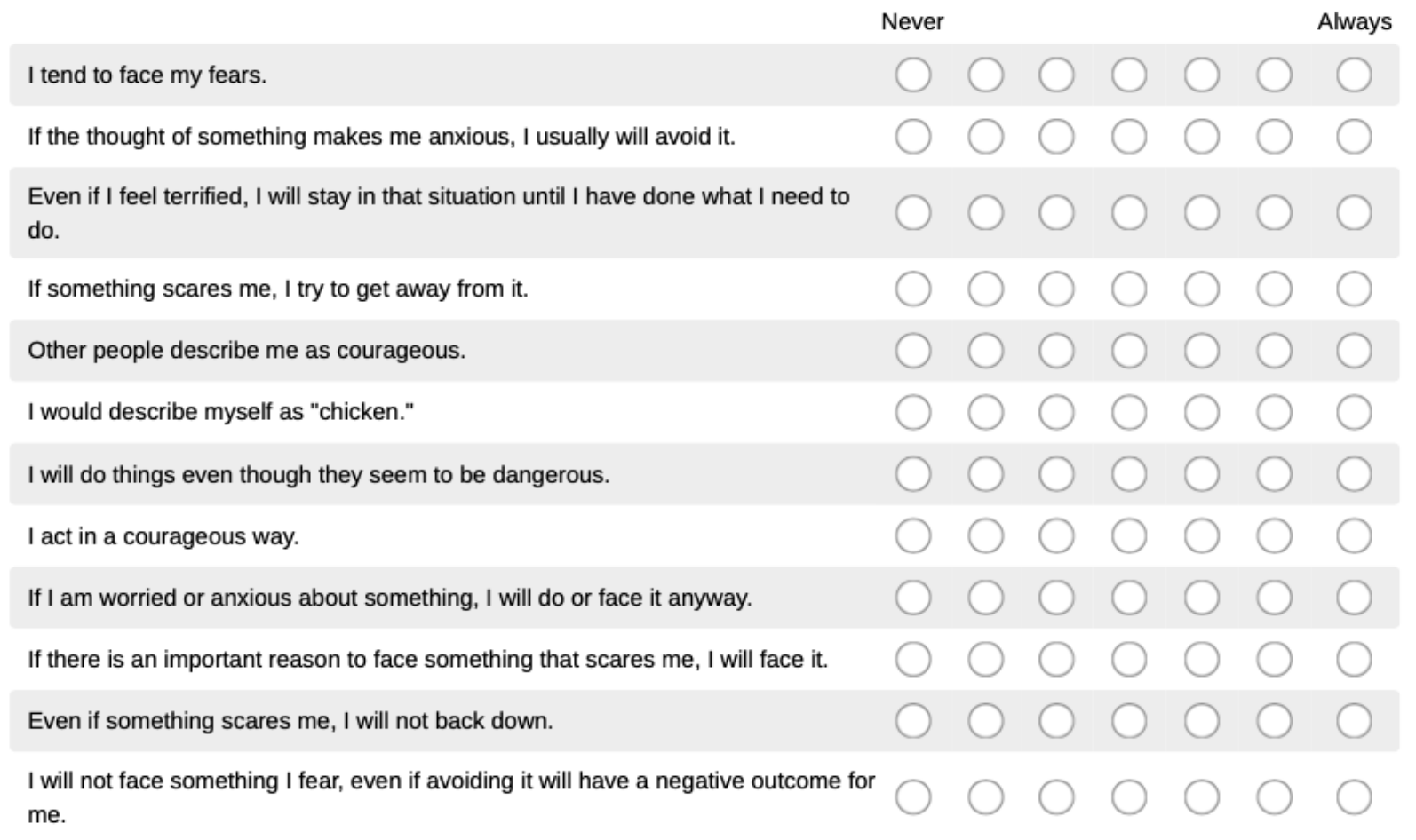




\section{Emotion Regulation Questionnaire for Children and Adolescents}

68. These are questions about what you feel like inside and how you show your feelings.

Please indicate how much you agree or disagree with each statement.

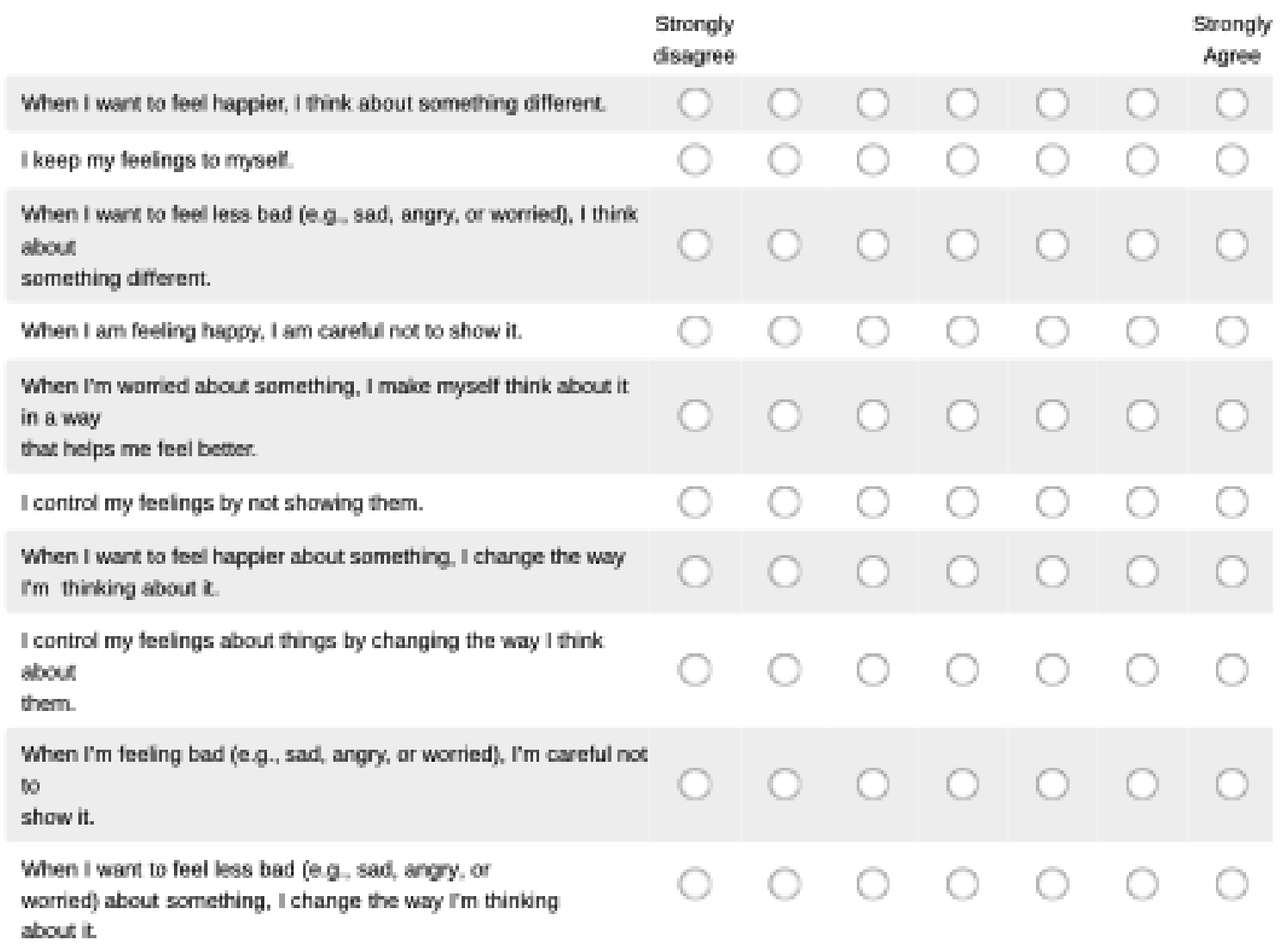




\section{Rosenberg Self-Esteem Scale}

141. Below is a list of statements dealing with your general feelings about yourself. Please indicate how strongly you agree or disagree with each statement.

On the whole, I am satisfied with myself.
At times I think I am no good at all.
I feel that I have a number of good qualities.
I am able to do things as well as most other people.
I feel I do not have much to be proud of.
I certainly feel useless at times.
I feel that I'm a person of worth, at least on an equal plane with
others.
I wish I could have more respect for myself.
All in all, I am inclined to feel that I am a failure.
I take a positive attitude toward myself.




\section{Parental Attachment - The Experiences in Close Relationships}

112. Please answer the following questions about your MOTHER or MOTHER-FIGURE.

I usually discuss my problems and concerns with this person.
I talk things over with this person.
It helps to tum to this person in times of need.
I find it easy to turn to this person.
I prefer not to show this person how' I feel.
I'm afraid this person might abandon me.
I worry that this person won't care about me as much as I care for
him or her.
I often worry that this person doesn't actually care for me.

113. Please answer the following questions about your FATHER or FATHER-FIGURE...

I usually discuss my problems and concerns with this person.
I talk things over with this person.
It helps to tum to this person in times of need.
I find it easy to turn to this person.
I prefer not to show this person how I feel.
I don't feel comfortable opening up to this person.
I worry that this person won't care about me as much as I care for
him or her.
I often worry that this person doesn't actually care for me.




\section{Parent Autonomy Granting - Parent Behavior Measure}

Please answer the questions for each person that you have a relationship with. Sometimes the answers for different people may be the same, but often they are different. If you do not have one of these relationships, leave that space blank on all of the questions.

114. I feel that this parent gives me enough freedom.

$\begin{array}{lccc} & \text { Strongly Agree } & \text { Agree } & \text { Disagree Strongly Disagree } \\ \text { Mother } & & O & 0\end{array}$

115. This parent allows me to choose my own friends without interfering too much.

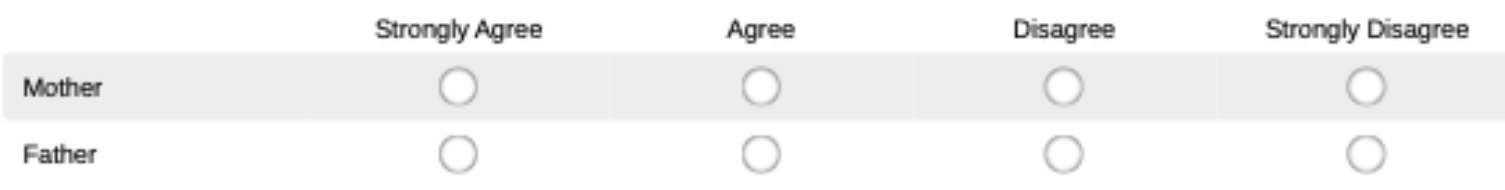

116. This parent allows me to decide what is right and wrong without interfering too much.

Mother $\quad$ Strongly Agree $\quad$ Agree

117. This parent allows me to decide what clothes I should wear without interfering too much.

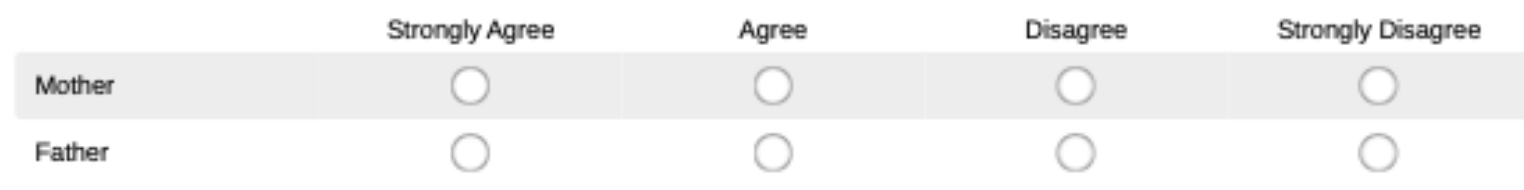

118. This parent allows me to choose my own dating partner without interfering too much.

Mother

119. This parent has confidence in my ability to make my own decisions.

Mother


120. This parent encourages me to help in making decisions about family matters.

Mother $\quad$ Strongly Agree $\quad$ Agree

121. This parent allows me to make my own decisions about career goals without interfering too much.

Mother

122. This parent allows me to make my own decisions about educational goals without interfering too much.

Mother

123. This parent lets me be my "own person" in enough situations.

$\begin{array}{lccc}\text { Mother } & \text { Strongly Agree } & \text { Disagree } & \text { Strongly Disagree } \\ \text { Father } & 0 & 0 & 0\end{array}$




\section{Helicopter Parenting Measure}

110. Please select the best answer for each of the following questions. My MOTHER or MOTHERFIGURE...

Makes important decisions for me (e.g., what activities I do, who
my friends are).
Intervenes in settling disputes with my classmates or friends.
Solves any crisis or problem I might have.
Looks for opportunities for me (e.g., jobs, internships, colleges).
intervenes in solving problems with my teachers, coaches, or
other adult leaders.

111. Please select the best answer for each of the following questions. My FATHER or FATHER-FIGURE...

Makes important decisions for me (e.g., what activities i do, who
my friends are).
Intervenes in settling disputes with my classmates or friends.
Solves any crisis or problem I might have.
Looks for opportunities for me (e.g., jobs, internships,
colleges).
Intervenes in solving problems with my teachers, coaches, or
other adult leaders.


Appendix B 
Regression models with neuroticism included as a covariate. Including personality

dimensions as covariates, eight hierarchical linear regression models were conducted to explore the contribution of adolescents' interpersonal and intrapersonal factors in explaining courage.

The standardized coefficients are presented in Tables 7 and 8. In the first step of all eight models, courage was regressed onto gender, SES ladder, and neuroticism (covariates). Each interpersonal and interpersonal factor was entered into the equations at step two. First, the covariates significantly predicted courage scores in the first step of all 8 models, accounting for $17-18 \%$ of the variance. After neuroticism was added to the model, both gender and SES were no longer significant in seven models (1 through 7; see Table 7 and 8), while neuroticism significantly predicted courage. Such results suggests that only adolescents with lower neuroticism reported greater courage. In model 8, SES and neuroticism significantly predicted courage in the first step of the model, such that adolescents higher on SES and lower on neuroticism reported greater courage (see Table 8 ).

In the second step of the models with mother-related variables, adolescents' avoidant and anxious attachment to mothers was not significant predictors of courage above and beyond the covariates (gender, SES ladder, and neuroticism). In the second step of the second model, autonomy support of mothers accounted for an additional $4 \%$ of the variance explained in courage, suggesting that autonomy support of mothers significantly predicted courage over and above the covariates (see Table 7). Greater autonomy support of mothers predicted significantly greater courage scores. In the third model, mothers' helicopter parenting added an additional 3\% of additional of the variance explained in courage. Greater helicopter parenting of mothers predicted significantly lower courage scores (see Table 7). 
In the second step of father-related variables, results indicated that adolescents' avoidant and anxious attachment with fathers were not significant predictors of courage above and beyond the covariates (standardized beta values are reported in Table 4). In the fifth model, autonomy support of fathers was not a significant predictor of courage. In the sixth model, helicopter parenting of fathers was not a significant predictor of courage. The standardized regression coefficients for all interpersonal variables (e.g., parenting-related) are reported in Table 7.

On the second step of the final two models with intra-personal variables, self-esteem was no longer a significant predictor of courage above and beyond the covariates (gender, SES, and neuroticism; see Table 8). In the eighth model, emotion regulation skills (e.g., cognitive reappraisal and expressive suppression) accounted for an additional $3 \%$ of the variance of courage. However, reappraisal and suppression were not significant predictors over and above the covariates, despite the model accounting for a significant amount of variance in courage (see Table 8). Such nonsignificant coefficients indicate that there was a fair amount of overlap among the variables predicting the value of courage, which explains why reappraisal and expression do not uniquely predict courage but the overall model accounts for the variance in courage.

\section{Exploratory mediational analyses with neuroticism as covariate. Additional} exploratory analyses were conducted with gender, SES ladder, and neuroticism as covariates. Compared to the earlier models, only two models were found to be significant.

The model, which included anxious attachment with mothers and self-esteem (and covariates) accounted for $19 \%$ of the variance in courage, $F(173)=8.37, p<.001$. As shown in Figure 11, the process through which anxious attachment of mothers was linked with courage was explained by self-esteem, even when controlling for neuroticism. Higher scores on the anxious attachment dimension of mothers were negatively and significantly related to self- 
esteem, which suggested that adolescents higher on the anxious attachment dimension of selfesteem. Self-esteem positively and significantly associated to courage. The direct effect of attachment anxiety of mothers to courage was not significant, $p=.31$ (see Figure 15). Such findings suggest adolescents with higher scores on attachment anxiety of mothers had lower selfesteem, which predicted less courage, over and above the effect of neuroticism, gender, and SES ladder.

The other set of model that included helicopter parenting of mothers and cognitive reappraisal (and covariates), accounted for $21 \%$ of the variance explained in courage, $F(181)=9.79, p<.001$. A significant indirect relationship between helicopter parenting of mothers and adolescents' courage through courage was found. As shown in Figure 16, maternal helicopter parenting was positively and significantly related with cognitive reappraisal, suggesting adolescents with higher scores on maternal helicopter parenting reported greater cognitive reappraisal. Cognitive reappraisal significantly predicted courage, suggesting adolescents who indicated greater maternal helicopter parenting utilized more cognitive reappraisal, which further predicted more courage. When neuroticism was included as a covariate, the negative direct effect of maternal helicopter parenting on courage was still significant, as well as the positive indirect effect (see Figure 16). Thus, findings suggest that maternal helicopter parenting continues to have a negative effect on courage over and above age, SES ladder, and neuroticism.

Surprisingly, when neuroticism was included in the models, most of the significant models (when only gender and SES were included) were found to be no longer significant, except for several of the mother-adolescent parenting associations. Such findings suggest that 
neuroticism plays a significant role in adolescent general courage, and may account for some of the findings relating to intrapersonal factors and fathers' parenting. 
Table 7

Hierarchical Regression Analysis for Interpersonal predictors of Time 3 Courage (with personality dimensions as covariates)

\begin{tabular}{|c|c|c|c|c|c|}
\hline Variable & $\begin{array}{l}\text { Step1 } \\
\text { Beta }\end{array}$ & $\begin{array}{l}\text { Step } 2 \\
\text { Beta }\end{array}$ & Variable & $\begin{array}{l}\text { Step1 } \\
\text { Beta }\end{array}$ & $\begin{array}{l}\text { Step } 2 \\
\text { Beta }\end{array}$ \\
\hline Model 1 & & & Model 4 & & \\
\hline Gender & .05 & .05 & Gender & .05 & .06 \\
\hline SES-Ladder & .10 & .11 & SES-Ladder & .11 & .11 \\
\hline Neuroticism & $-.36^{* * * *}$ & $-.36^{* * *}$ & Neuroticism & $-.35^{* * *}$ & $-.37^{* * *}$ \\
\hline Attachment Avoidant Mother & - & -.05 & Attachment Avoidant Father & - & -.08 \\
\hline Attachment Anxiety Mother & - & .05 & Attachment Anxiety Father & - & .12 \\
\hline$R^{2}$ & $.17^{* * *}$ & .17 & $R^{2}$ & $.17^{* * *}$ & .17 \\
\hline$\Delta R^{2}$ & .17 & .00 & $\Delta R^{2}$ & .17 & .01 \\
\hline Model 2 & & & Model 5 & & \\
\hline Gender & .07 & .05 & Gender & .07 & .04 \\
\hline SES-Ladder & .08 & .07 & SES-Ladder & .12 & .12 \\
\hline Neuroticism & -.37 & -.34 & Neuroticism & -.36 & -.34 \\
\hline Autonomy Support Mother & - & $.21^{* *}$ & Autonomy Support Father & - & .12 \\
\hline$R^{2}$ & $.18^{* * * *}$ & $.22^{* * *}$ & $R^{2}$ & $.18^{* * *}$ & .20 \\
\hline$\Delta R^{2}$ & .18 & $.04^{* * *}$ & $\Delta R^{2}$ & .18 & .01 \\
\hline Model 3 & & & Model 6 & & \\
\hline Gender & .06 & .06 & Gender & .07 & .07 \\
\hline SES-ladder & .10 & .08 & SES-ladder & .10 & .10 \\
\hline Neuroticism & -.36 & -.36 & Neuroticism & $-.37^{* * *}$ & $-.37^{* * * *}$ \\
\hline Helicopter Parenting Mother & - & $-.16^{*}$ & Helicopter parenting Father & - & -.00 \\
\hline$R^{2}$ & .17 & $20^{* * * *}$ & $R^{2}$ & $.18^{* * *}$ & .18 \\
\hline$\Delta R^{2}$ & .17 & $.03^{*}$ & $\Delta R^{2}$ & .18 & .00 \\
\hline
\end{tabular}

Note. ${ }^{*} p<.05 . * * p<.01 . * * * p<.001$. Coefficients reported are standardized coefficients. 


\section{Table 8}

Hierarchical Regression Analysis for Intrapersonal predictors of Time 3 Courage (with personality dimensions as covariates)

\begin{tabular}{lcc}
\hline Variable & Step1 & Step 2 \\
\hline Model 7 & & \\
Gender & .07 & .07 \\
SES-Ladder & .10 & .07 \\
Neuroticism & $-.37^{* * *}$ & $-.26^{*}$ \\
Self-esteem & - & .17 \\
\cline { 2 - 3 }$R^{2}$ & $.19^{* * *}$ & .20 \\
$\Delta R^{2}$ & .19 & .01 \\
\hline Model 8 & & \\
Gender & .06 & .07 \\
SES-Ladder & .11 & $.14^{*}$ \\
Neuroticism & $-.36^{* * *}$ & $-.33^{* * *}$ \\
Cognitive Reappraisal & - & .11 \\
Expressive Suppression & - & .13 \\
$R^{2}$ & $.17^{* *}$ & $.20^{* * *}$ \\
$\Delta R^{2}$ & .17 & $.03^{*}$ \\
\hline
\end{tabular}

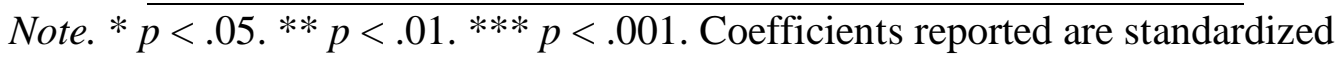
coefficients. 


\section{Figure 9}

Mediating effect of self-esteem on the relationship between autonomy support of mother and courage. $N=184$. Gender, SES ladder, and neuroticism are included as covariates.

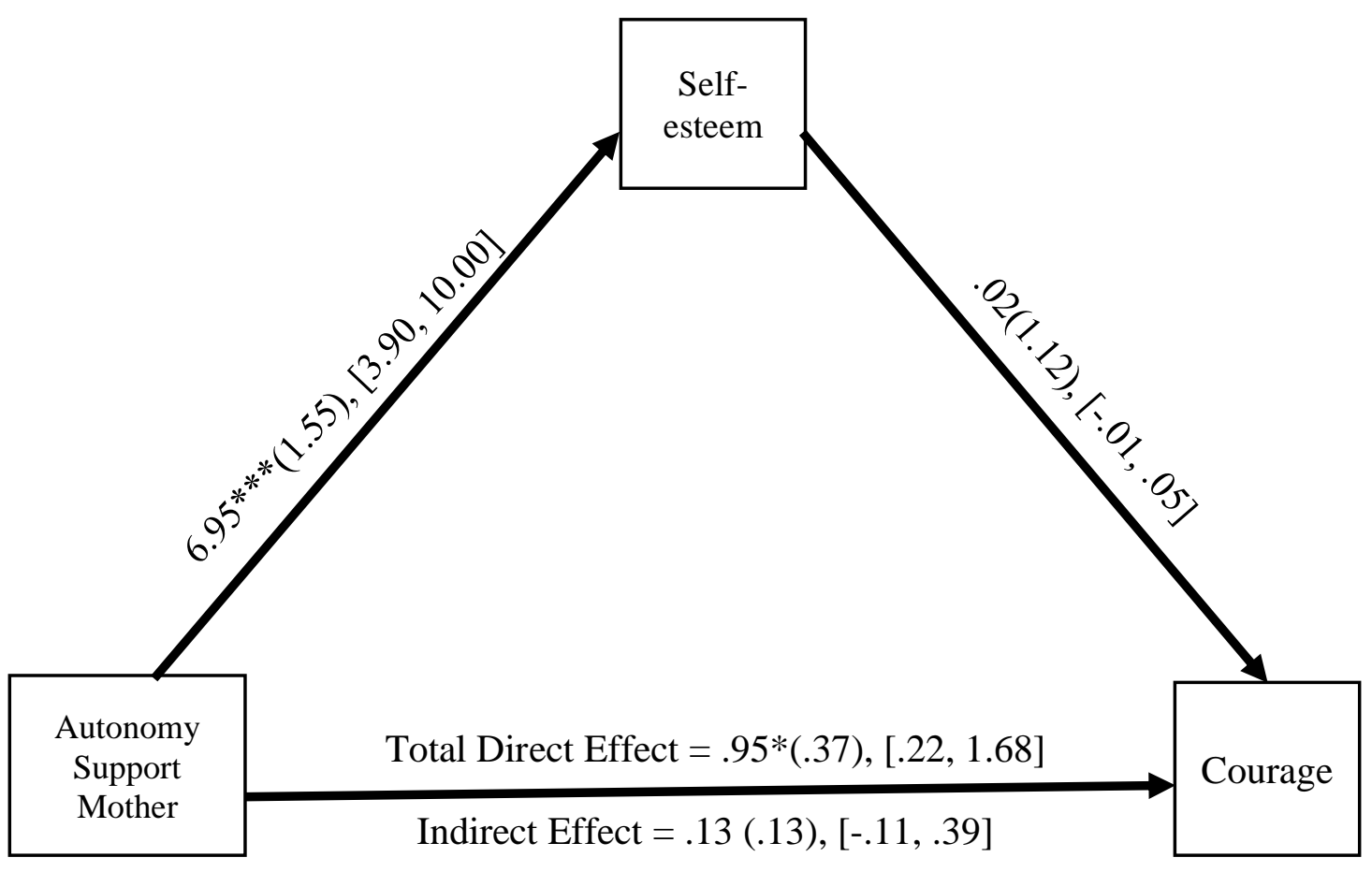

Figure 10

Mediating effect of self-esteem on the relationship between autonomy support of father and courage. $N=176$.

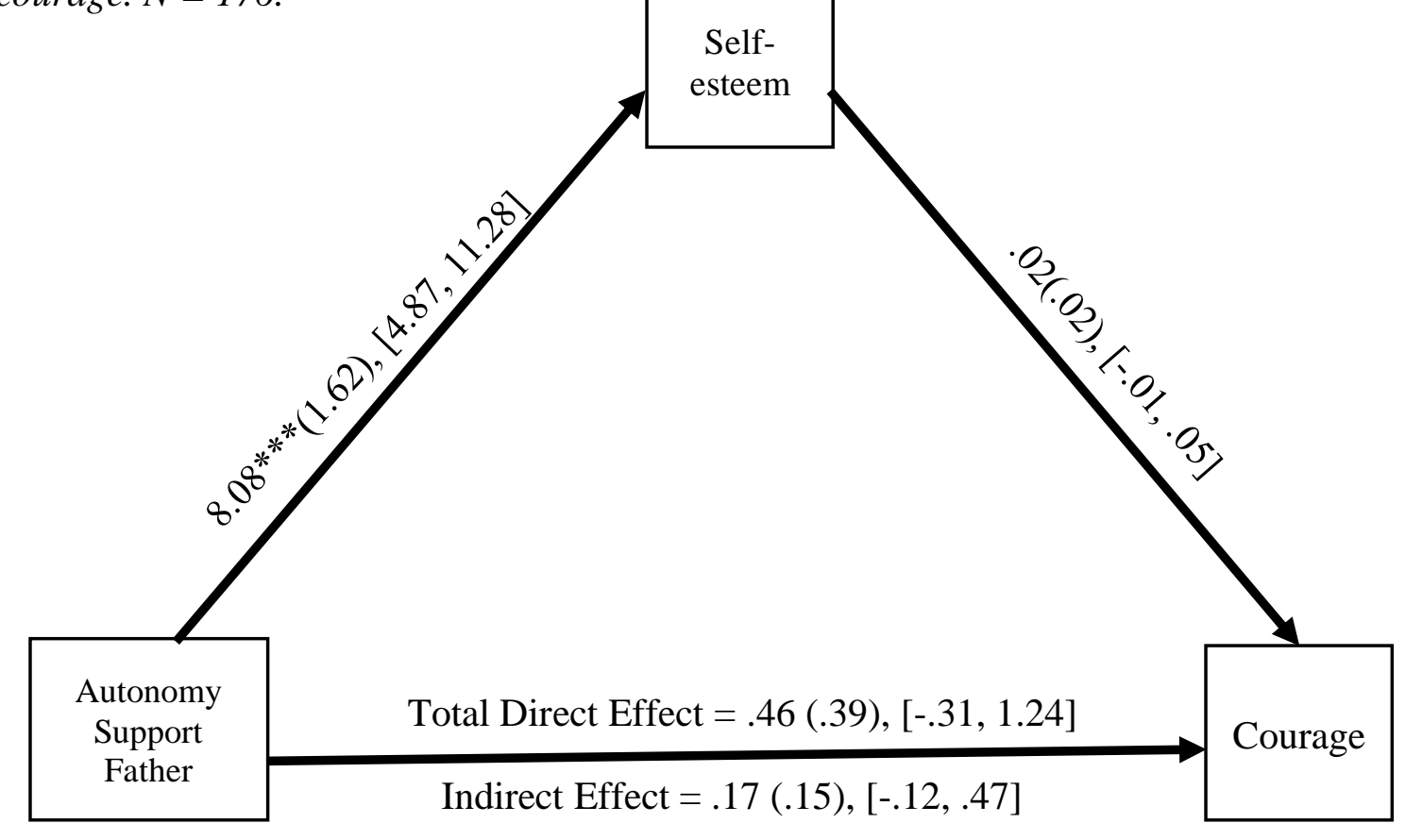




\section{Figure 11.}

Mediating effect of self-esteem on the relationship between attachment-anxious to mother and courage. $N=179$. Gender, SES ladder, and neuroticism are included as covariates.

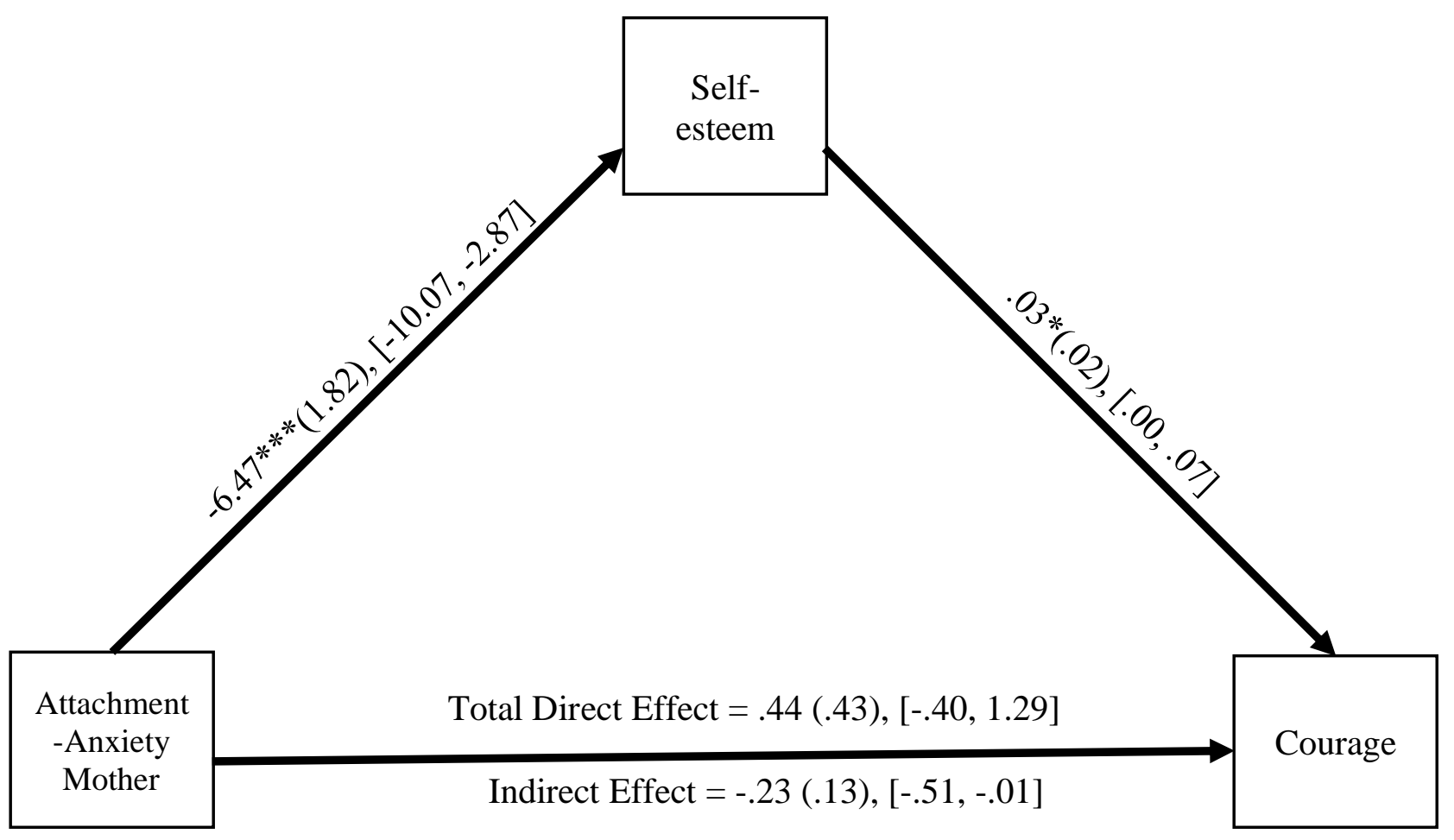

Figure 12

Mediating effect of self-esteem on the relationship between attachment-anxious to father and courage. $N=176$. Gender, SES ladder, and neuroticism are included as covariates.

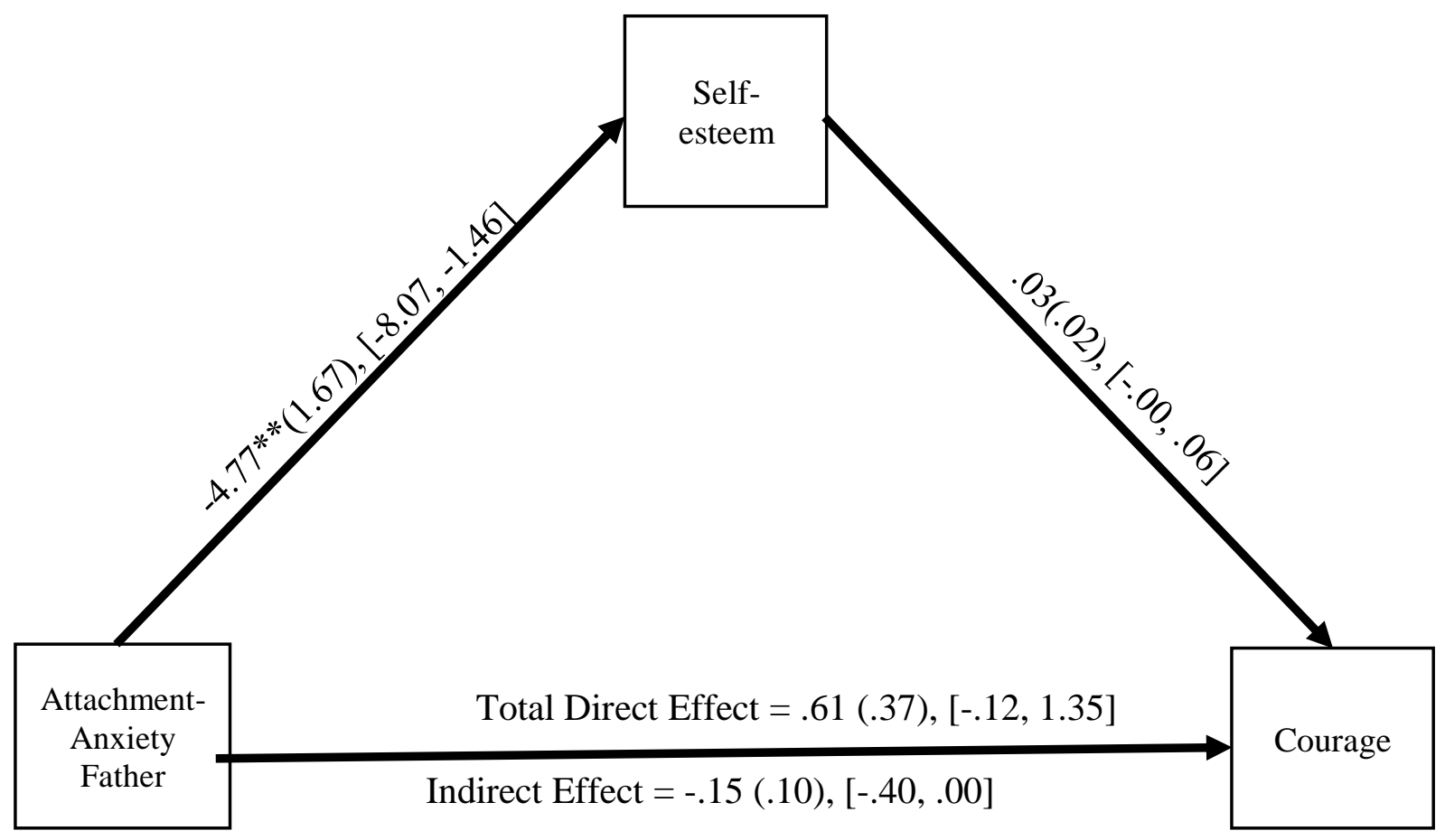




\section{Figure 13}

Mediating effect of self-esteem on the relationship between attachment-avoidant to mother and courage. $N=184$. Gender, SES ladder and neuroticism are included as covariates.

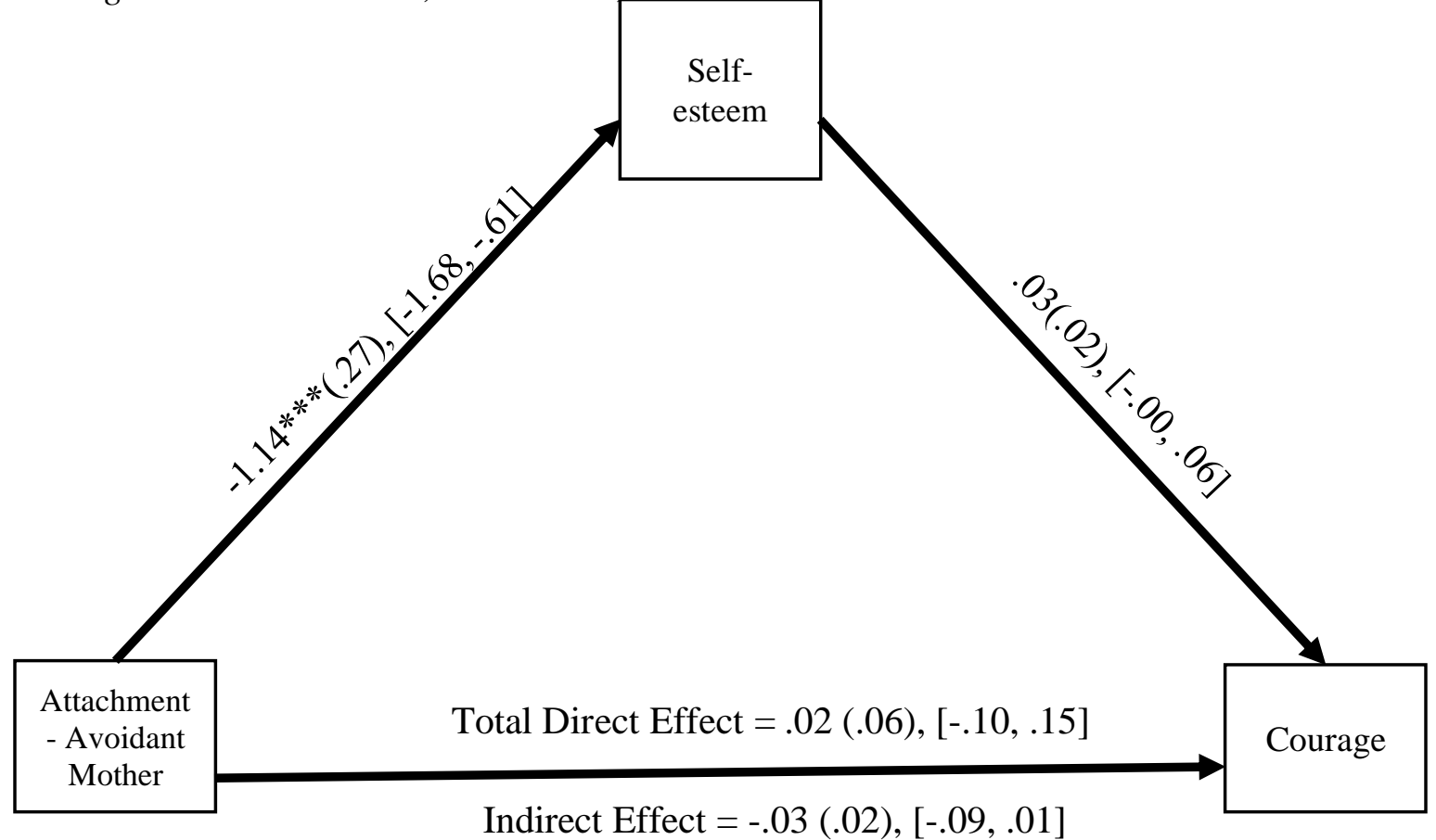

\section{Figure 14}

Mediating effect of self-esteem on the relationship between attachment- avoidant to father and courage. $N=177$. Gender, SES ladder, and neuroticism are included as covariates.

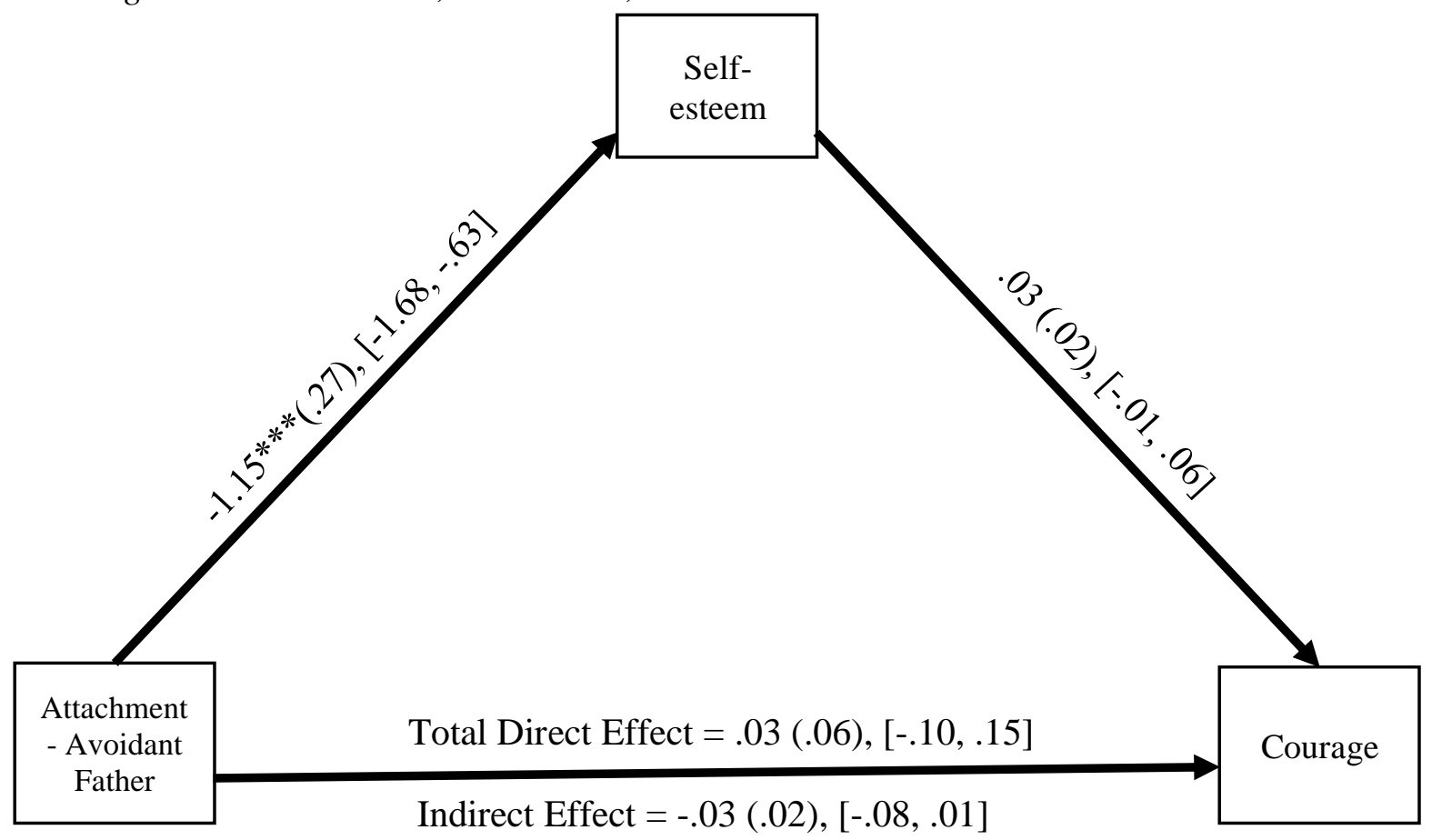




\section{Figure 15}

Mediating effect of cognitive reappraisal on the relationship between avoidant attachment to mother and courage. $N=186$. Gender, SES ladder, and neuroticism are included as covariates.

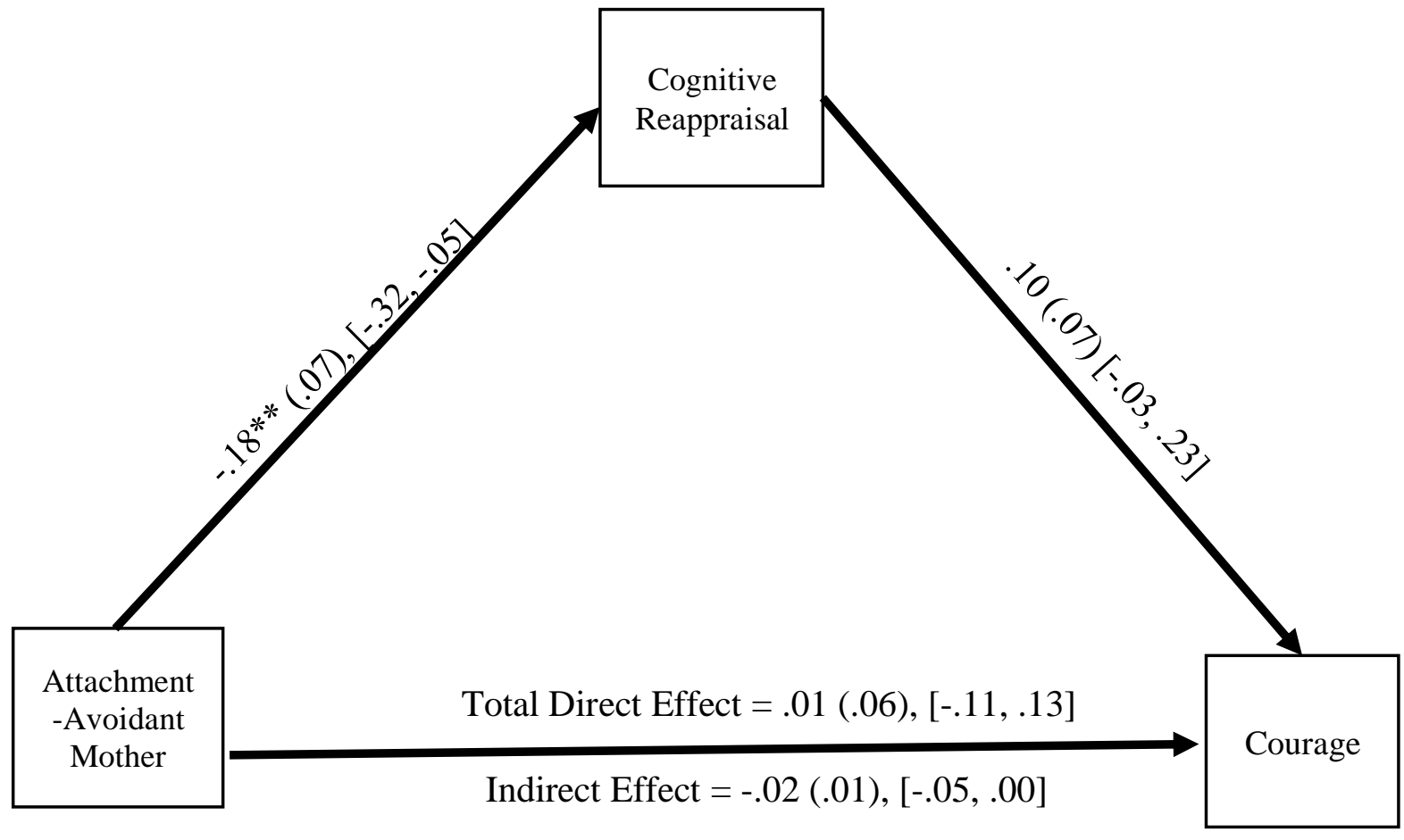

\section{Figure 16}

Mediating effect of cognitive reappraisal on the relationship between helicopter parenting of mothers and courage. $N=187$. Gender, SES ladder, and neuroticism are included as covariates.

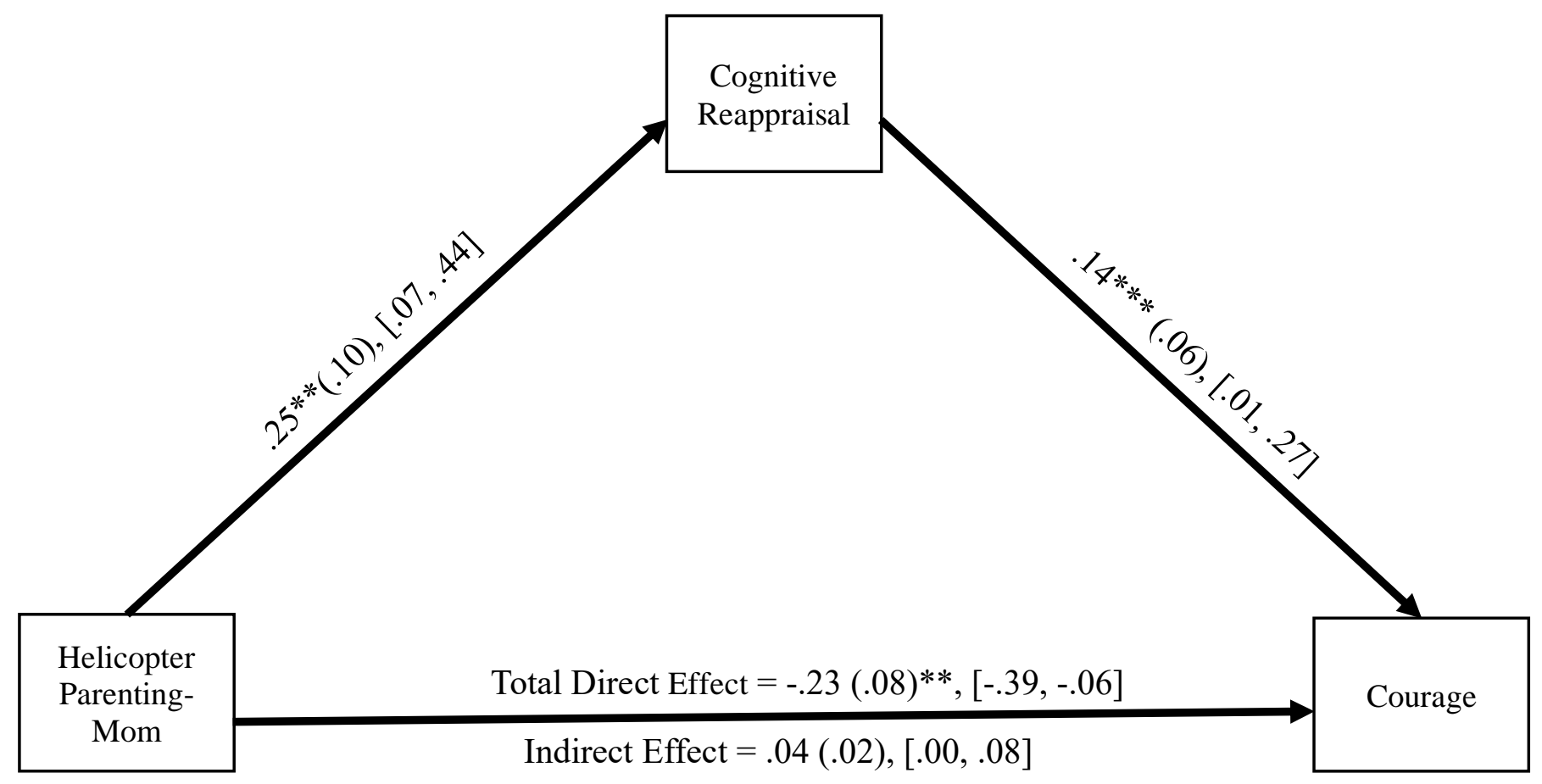

